\title{
Cognitive Control Deficits in Schizophrenia: Mechanisms and Meaning
}

\author{
Tyler A Lesh ${ }^{1}$, Tara A Niendam ${ }^{1}$, Michael J Minzenberg ${ }^{1}$ and Cameron S Carter, \\ ${ }^{1}$ Department of Psychiatry, UC Davis Imaging Research Center, Davis School of Medicine, University of California, \\ Sacramento, CA, USA
}

\begin{abstract}
Although schizophrenia is an illness that has been historically characterized by the presence of positive symptomatology, decades of research highlight the importance of cognitive deficits in this disorder. This review proposes that the theoretical model of cognitive control, which is based on contemporary cognitive neuroscience, provides a unifying theory for the cognitive and neural abnormalities underlying higher cognitive dysfunction in schizophrenia. To support this model, we outline converging evidence from multiple modalities (eg, structural and functional neuroimaging, pharmacological data, and animal models) and samples (eg, clinical high risk, genetic high risk, first episode, and chronic subjects) to emphasize how dysfunction in cognitive control mechanisms supported by the prefrontal cortex contribute to the pathophysiology of higher cognitive deficits in schizophrenia. Our model provides a theoretical link between cellular abnormalities (eg, reductions in dentritic spines, interneuronal dysfunction), functional disturbances in local circuit function (eg, gamma abnormalities), altered inter-regional cortical connectivity, a range of higher cognitive deficits, and symptom presentation (eg, disorganization) in the disorder. Finally, we discuss recent advances in the neuropharmacology of cognition and how they can inform a targeted approach to the development of effective therapies for this disabling aspect of schizophrenia.

Neuropsychopharmacology Reviews (2011) 36, 316-338; doi: I 0. I038/npp.20 I0.156; published online I5 September 2010
\end{abstract}

Keywords: cognitive control; schizophrenia; cognition; disorganization; prefrontal cortex; executive functioning

\section{INTRODUCTION}

Cognitive dysfunction represents a core deficit in schizophrenia, and a number of studies (Green, 1996; Green et al, 2000) illustrate how cognitive deficits may strongly influence the clinical presentation and daily functioning of people with this illness. Cognitive deficits in schizophrenia have been associated with disorganization and negative symptoms (eg, see Cohen et al, 1999; Green et al, 2000; Kerns and Berenbaum, 2002) as well as with poor functional outcomes (Green, 1996, 1998; Weinberger and Gallhofer, 1997). Despite these links, cognitive dysfunction shows only modest improvement with currently available therapies and the vast majority of patients treated with second-generation antipsychotic drugs continue to experience significant

*Correspondence: Dr CS Carter, Department of Psychiatry, UC Davis Imaging Research Center, Davis School of Medicine, University of California, $4701 \times$ Street, Suite E, Sacramento, CA 95817, USA,

Tel: +1 916734 7783; Fax: +1916 734 8750,

E-mail: cameron.carter@ucdmc.ucdavis.edu

Received 19 March 2010; revised 11 August 2010; accepted 11 August 2010 cognitive disability (Green, 1998; Harvey and Keefe, 2001; Weinberger and Gallhofer, 1997). In response to the increased awareness of the clinical importance of impaired cognition in schizophrenia, there has been a dramatic increase in research directed toward understanding the pathophysiological mechanisms underlying these deficits as well as developing effective therapies for this aspect of the illness.

Previous studies in schizophrenia have utilized standardized neuropsychological batteries to examine various aspects of cognition in the disorder. Findings reveal that cognitive deficits are present in schizophrenia regardless of illness stage, as individuals experiencing their first episode of schizophrenia show a pattern of deficits on tasks related to frontal and temporal lobe functioning, including attention, processing speed, executive functioning, verbal fluency, verbal memory, and learning (Censits et al, 1997; Hoff et al, 1992; Mohamed et al, 1999; Riley et al, 2000; Saykin et al, 1994; Schuepbach et al, 2002; Townsend et al, 2001). Deficits in these domains have been consistently associated with poor social functioning as well as poor work/school outcome (Addington and Addington, 1999; 
Addington et al, 1998; Bell and Bryson, 2001; Bilder et al, 2000; Bowen et al, 1994; Brekke et al, 1997; Corrigan and Toomey, 1995; McGurk and Meltzer, 2000a; Smith et al, 2002; Velligan et al, 2000). Furthermore, impairment in such cognitive domains has been associated with negative and disorganization symptoms, including formal thought disorder (Addington and Addington, 1999, 2000; Bilder et al, 2000; Breier et al, 1991; Cohen et al, 1999; Dibben et al, 2009; Dickerson et al, 1996; Goldman et al, 1993; Greenwood et al, 2008; Heslegrave et al, 1997; Kerns and Berenbaum, 2002; Lenior et al, 2001; MacDonald et al, 2005; McGurk and Meltzer, 2000a; McGurk et al, 2000b; Moriarty et al, 2001; Perlstein et al, 2001; Velligan et al, 1997; Yoon et al, 2008a). Moreover, cognitive improvement in schizophrenia is typically associated with a reduction in negative symptoms, but not positive symptoms (Censits et al, 1997; Mohamed et al, 1999; Schuepbach et al, 2002).

Although previous studies have revealed important information with regard to the impact of impaired cognition in schizophrenia, the use of standard neuropsychological measures limits our ability to understand the complexity of the underlying impairment, as a particular test may engage numerous cognitive processes (Cho et al, 2005). One example is the Wechsler Digit Symbol-Coding subtest (Wechsler, 1997), which shows one of the most reliably documented impairments in the clinical neuropsychological literature of schizophrenia (Dickinson et al, 2007). Although this task is typically categorized as a measure of attention, accurate and rapid performance requires simple visual attention, active maintenance of symbol-digit pairings in working memory, as well as psychomotor speed. Thus, interpretation of lower performance in a patient population is difficult, as poor performance may be owing to an isolated deficit in any one of the component processes mentioned above and/or a deficit in the fluid integration of these processes. Consequently, the recruitment of multiple cognitive processes during a task restricts the ability to isolate specific neural systems and accurately identify functional neural markers of risk.

In response to these limitations, research utilizing cognitive science paradigms that isolate particular cognitive processes within schizophrenia has increased dramatically over the past decade. Within the domain of higher cognitive functions, disturbances have been described in selective attention (Carter et al, 1992; Cornblatt et al, 1989; Mirsky, 1969; Nuechterlein and Dawson, 1984), working memory (Carter et al, 1996; Glahn et al, 2000; Gold et al, 1997; Keefe et al, 1995; Park and Holzman, 1992), episodic memory (Clare et al, 1993; Ranganath et al, 2008; Saykin et al, 1991; Schwartz et al, 1992; Tamlyn et al, 1992), language production (Barch and Berenbaum, 1996a; Docherty et al, 1988, 1996; Harvey, 1983), and comprehension (Condray et al, 1995; Morice and McNicol, 1985). Although it is possible that schizophrenia patients have discrete deficits in multiple cognitive systems, a parsimonious account of many of these deficits, as suggested by Kraepelin a century ago (Kraepelin $(1919,1971)$, 'The mind in dementia praecox is like an orchestra without a conductor'), is that they reflect impaired cognitive control.

This review proposes that the theoretical model of cognitive control, which is based on contemporary cognitive neuroscience, provides a unifying theory for the cognitive and neural abnormalities underlying higher cognitive dysfunction in schizophrenia. In support of this theory, we summarize the literature on impaired cognition in schizophrenia as well as in high-risk populations and discuss the clinical and etiological significance of these deficits. In doing so, we hope to provide background and rationale for an integrative cognitive control account of these seemingly unique and disparate findings. Finally, we will outline how this model can inform a critical research agenda that is focused on developing effective therapies to reduce disability associated with the illness.

\section{A MODEL OF HIGHER COGNITIVE DEFICITS IN SCHIZOPHRENIA: IMPAIRED COGNITIVE CONTROL, DISORGANIZATION, AND THE PREFRONTAL CORTEX}

In order to manage the complex set of demands that come with day-to-day life, the human brain has developed mechanisms to coordinate the multitude of incoming sensory and motor information with higher-level representations of internal goals or rules to determine appropriate behavioral responses. The adequate engagement of cognitive control requires the coordination of multiple brain regions, including the dorsolateral prefrontal cortex (DLPFC), medial frontal cortex (including the anterior cingulate cortex), and parietal regions (Botvinick et al, 2001; Carter et al, 1999; Cohen et al, 2000; Yarkoni et al, 2005). Owing to its interconnectivity with sensory and motor regions, the DLPFC is believed to have a central role in the maintenance of the rules for action as well as response selection (Asaad et al, 2000; Watanabe, 1990, 1992). In contrast, medial frontal regions, specifically the anterior cingulate cortex (ACC), are believed to detect response conflict as part of a 'control loop' and then signal the DLPFC when control-related activity should be increased to improve performance (Egner and Hirsch, 2005; Kerns et al, 2005; MacDonald et al, 2000). The activation of parietal regions provides the DLPFC with the ability to shift attentional focus and provides information on learned stimulus-response pairings (Bunge et al, 2002, 2003; Miller and Cohen, 2001; Posner and Petersen, 1990). When engaged in tasks requiring cognitive control, functional neuroimaging studies of healthy individuals have shown activation of a specific cortical network, including the DLPFC and anterior cingulate cortex (Brass and von Cramon, 2002; Braver et al, 2003; Dove et al, 2000; Dreher et al, 2002; Liston et al, 2006; Sohn et al, 2000; Yeung et al, 2006). When such prefrontal brain regions are damaged, affected individuals show predictable deficits in context maintenance and response inhibition (Miller, 2000). 
Early studies of the prefrontal cortex (PFC) structure and function in non-human primates (Funahashi et al, 1993; Fuster, 1990; Goldman-Rakic, 1987; Jacobsen, 1936) suggested that the PFC serves as a temporary storage for incoming information, maintaining it 'online' for immediate use. However, more recent views of the PFC suggest that its role is much more complex (Braver et al, 2002; Bunge et al, 2002; D'Esposito and Postle, 2002; Fuster, 2002; Thompson-Schill et al, 2005). Although a complete discussion of this literature is beyond the scope of this review, it is important to summarize our current understanding of the PFC and its role in cognitive control. Given its extensive interconnections with sensory, motor, and subcortical regions, the PFC is believed to serve a primary role in integrating incoming information and providing 'top-down' processing to coordinate behavior (Miller, 2000; Miller and Cohen, 2001). Information processing in the brain is often competitive as different information is received from various pathways, leading to a competition for the selection of a behavioral response. In concordance with early theories of the PFC as 'online storage,' Miller and Cohen (2001) propose that the PFC actively maintains 'rules' online in order to evaluate incoming information as well as internal states to guide response selection toward a current goal. When we are confronted with conflicting behavioral responses, the PFC provides 'cognitive control' by maintaining the set of rules that are required to be successful in a new situation and constrains neural information processing across the brain in accordance with these rules and goals. By doing so, the PFC biases neural processing in the brain away from prepotent but incorrect responses and toward the appropriate response. Figure 1 illustrates this phenomenon using the Stroop task, in which the 'high control' condition of color naming requires greater engagement of the PFC to overcome the prepotent response of word reading. In this way, the PFC is responsible for maintaining goals and rules and binding them with incoming sensory and motor information to direct attention to task-relevant information.

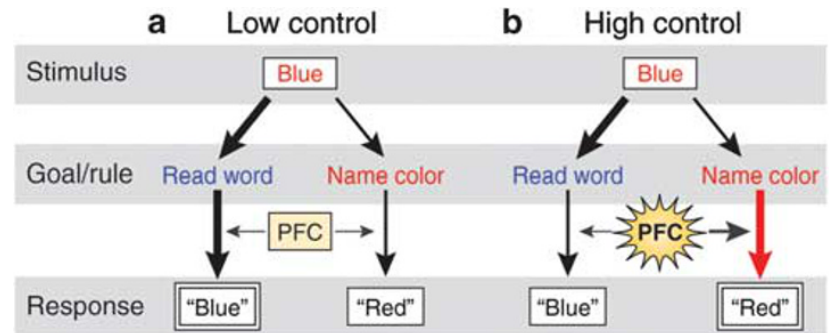

Figure 1. Simplified graphical depiction of the role of the prefrontal cortex (PFC) during the classic Stroop task, in which the stimulus is identical but the engagement of control processes is modulated by the rule. (a) Under low cognitive control demands (ie, word reading), the PFC is minimally engaged and the response is biased towards the prepotent word reading response, which is represented by relatively thicker black vertical arrows. (b) In contrast, under high cognitive control demands (ie, color naming), the PFC is strongly recruited to bias responding away from the prepotent response and toward the appropriate response represented by the large red vertical arrow.
This in turn biases information processing and response selection toward responses that are relevant for the goal at hand, and facilitates the updating of these rules and goals based on reward and ongoing experience (Miller and Cohen, 2001).

It is important to note that cognitive control processes encompass a broad class of mental operations, including goal or context representation and maintenance, strategic processes such as attention allocation and stimulusresponse mapping, and performance monitoring (Carter et al, 1998; Cohen et al, 1990; Miyake and Shah, 1999; Shallice, 1988). Cognitive control is associated with a wide range of cognitive processes (Carter et al, 1998; Posner and Abdullaev, 1996) and is not restricted to a particular cognitive domain (Banich, 1997; Smith and Jonides, 1999). Therefore, cognitive control represents the overarching ability to maintain context for appropriate behavior in a given situation in the face of interference (such as through the activation of prepotent response tendencies) and impaired cognitive control would be expected to lead to a range of cognitive deficits across a broad range of 'domains' of higher cognition. The model of cognitive control deficits in schizophrenia described in this paper focuses on the contribution of the DLPFC in maintaining task context and guiding processing across the brain in a task appropriate manner.

\section{COGNITIVE CONTROL DEFICITS IN SCHIZOPHRENIA: EVIDENCE FOR A PREFRONTALLY BASED DISORGANIZATION SYNDROME}

Research on the role of the DLPFC has been a topic of interest to schizophrenia researchers for over three decades, as early studies of cerebral blood flow showed reductions in anterior to posterior resting gradients in patients (Ingvar and Franzen, 1974). Follow-up studies by Weinberger et al (1986) showed reduced activity in the DLPFC during the Wisconsin Card Sorting task for both medicated and unmedicated patients. Since those studies, many authors have reported decreased prefrontal activation (see Andreasen et al (1992) and Buchsbaum et al (1996) for early reviews or Glahn et al (2005) for a more recent review of activation studies). Such findings are not consistently reported across the literature (Glahn et al, 2005; Gur and Gur, 1995; Manoach et al, 1999), and this may be related to the selection of tasks that do not reliably activate the DLPFC in healthy controls (Carter et al, 1998; Taylor et al, 1994). Previous studies in our lab have consistently observed reduced DLPFC activity during cognitive control tasks in schizophrenia, which has been associated with impaired task performance and behavioral disorganization (Barch et al, 2001; Carter et al, 1998; MacDonald et al, 2005; Perlstein et al, 2001; Snitz et al, 2005; Yoon et al, 2008a) irrespective of patient medication status (MacDonald et al, 2005). Interestingly, although DLPFC activity has been reliably decreased in these studies, 
posterior regions of VLPFC show normal activation patterns in patients (Barch et al, 2001; MacDonald et al, 2005; Perlstein et al, 2001), suggesting a pattern of reduced DLPFC activation with normal VLPFC functioning in schizophrenia (Glahn et al, 2005; Wolf et al, 2007). A meta-analysis of 41 neuroimaging studies of executive function in schizophrenia revealed similar findings of reduced activation in patients within bilateral DLPFC, ACC, and mediodorsal thalamus (Figure 2; Minzenberg et al, 2009).

Recently, Yoon et al (2008b) utilized fMRI and an abbreviated version of the AX-Continuous Performance Task (AX-CPT) to examine the relationship between DLPFC activation and cognitive and psychosocial functioning in the early phase of schizophrenia. In the AX-CPT, subjects make a target response to the probe letter $\mathrm{X}$, only when it follows the cue letter $A$. All other stimuli require a non-target response, including trials in which $\mathrm{X}$ is preceded by any letter other than A (collectively referred to as cue B trials). Trials with target (AX) cue-probe pairings occur with high frequency $(70 \%)$, setting up the tendency to make a target response to the $\mathrm{X}$ probe. The $\mathrm{BX}$ condition requires the highest cognitive control, as subjects must overcome the tendency to make a target response to X. First episode schizophrenia participants showed a pattern indicating poor cognitive control with increased $\mathrm{BX}$ relative to $\mathrm{AY}$ errors, which is consistent with previous findings of a specific deficit in first episode individuals (MacDonald and Carter, 2003a), and this impairment was associated with reduced activation of the DLPFC when compared with normal controls. Using the beta series correlation method (Rissman et al, 2004), whole-brain functional connectivity was measured by examining within-subjects correlations between the time series in the DLPFC seed region and the rest of the voxels in the brain. In control subjects, DLPFC activity during this task was correlated with the activation of a distributed frontoparietal network required to support optimal task performance. In contrast, first episode patients showed a significant reduction of DLPFC-related functional connectivity, as they did not engage the same frontoparietal network under conditions requiring high cognitive control. Importantly, the level of DLPFC connectivity was associated with increased symptoms of disorganization and poorer psychosocial functioning in the first episode sample. This pattern of results is strongly consistent with the notion that impaired PFC function is associated with an inability to exert top-down control over the task appropriate distributed network and suggests a basis for the association between a PFC-based disorganization syndrome in schizophrenia and functional impairment in the illness.

As noted previously, individuals with schizophrenia show cognitive impairment in other domains, such as episodic memory (Aleman et al, 1999). Structural abnormalities in medial temporal regions found in individuals with schizophrenia (Shenton et al, 2001; Steen et al, 2005), specifically the hippocampal region (Heckers, 2001), may contribute to the observed impairment in memory functioning. However, recent meta-analyses (Ragland et al, 2009; Ranganath et al, 2008) suggest that episodic memory impairment in schizophrenia may be, in part, the result of impaired prefrontal cognitive control mechanisms, which help to guide encoding and retrieval processes. Specifically, Ragland et al (2009) examined 18 functional neuroimaging studies of episodic memory encoding and retrieval in individuals with schizophrenia and healthy controls. Results showed decreased activation of prefrontal regions, including the dorsolateral and ventrolateral prefrontal cortices, but not medial temporal regions during encoding and retrieval when compared with healthy controls. When the participants were provided with an encoding strategy, decreased activation was still observed in the dorsolateral prefrontal region, with no difference observed in the ventrolateral prefrontal region, suggesting that this area may serve to compensate for continued impairment in dorsolateral prefrontal functioning. In contrast to expectation, no reliable findings were found in the hippocampus, whereas increased activation was observed in the parahippocampal gyrus during encoding and retrieval, which was again interpreted as serving a potential compensatory role. Taken together, these findings suggest that prefrontal cognitive control deficits may be related to many aspects of cognitive impairment that are associated with schizophrenia.

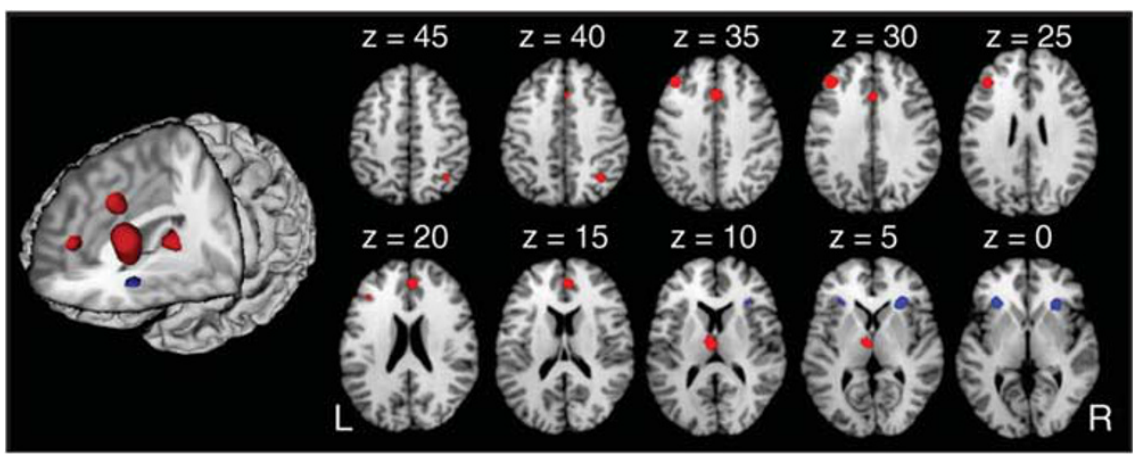

Figure 2. Regions in which patients with schizophrenia showed co-occurring hypoactivation compared with controls across a full set of executive function studies (reprinted with permission from Minzenberg et al, 2009). 


\section{COGNITION AS A MARKER OF RISK FOR SCHIZOPHRENIA AND THE RELATIONSHIP TO COGNITIVE CONTROL}

In addition to its role as a predictor of clinical and psychosocial functioning for those individuals diagnosed with schizophrenia, impaired cognition may also represent an endophenotype, or intermediate trait that lies between an underlying genetic vulnerability and expression of the clinical phenotype that can be used to identify individuals at greatest risk for the illness. Unaffected first-degree relatives of individuals with schizophrenia consistently show deficits on measures of executive function and processing speed (Egan et al, 2001a; Faraone et al, 1995; Franke et al, 1993; Keefe et al, 1994; Kuha et al, 2007), attention (Faraone et al, 1995, 1999; Finkelstein et al, 1997; Mulet et al, 2007), and verbal memory (Faraone et al, 1995, 1999; Habets et al, 2008). Cannon et al (2000b) showed that frontally mediated deficits on neuropsychological measures of attention and working memory were associated with increasing genetic liability to schizophrenia and were equally impaired in affected and unaffected monozygotic (MZ) co-twins, whereas deficits in temporally mediated verbal episodic memory were significantly more pronounced in the affected members of discordant MZ pairs. This finding supported previous work by Harris et al (1996), who showed that a subset of relatives in multiply affected families showed deficits on a measure of set shifting and processing speed when compared with normal controls.

A recent meta-analysis by Snitz et al (2006) showed that first-degree relatives showed a wide range of effect sizes across tasks, with the largest effect sizes seen on Trails B, CPT-X d-prime, and CPT-AX/-IP d-prime and false alarms. The authors concluded that cognitive deficits, particularly those involving executive control, working memory, and inhibition, may be the most likely to yield positive results in the search for genes conferring risk for schizophrenia. These data, along with evidence of cognitive dysfunction early in childhood (Cannon et al, 2000a; Cornblatt et al, 1999; Erlenmeyer-Kimling et al, 2000; Jones et al, 1994; Niendam et al, 2003; Russell et al, 1997) and impaired cognition at the onset of the illness, implicate a neurodevelopmental pathophysiological mechanism that leads to illness onset.

\section{EVIDENCE FOR COGNITIVE CONTROL DEFICITS IN GENETIC HIGH-RISK SAMPLES}

Given strong evidence of morphometric, functional, and behavioral dysfunction of the PFC and associated cognitive control tasks in patients, a body of work has examined whether cognitive control deficits are associated with a genetic liability for the disorder. Many studies have highlighted impairment in frontally mediated executive functions in both adult (Cannon et al, 2000b; Egan et al, 2001a; Faraone et al, 1995; Finkelstein et al, 1997; Franke et al, 1993; Keefe et al, 1994) and child genetic high-risk samples (Cornblatt, 2002; Cosway et al, 2000; Johnstone et al, 2002; Wolf et al, 2002). More specifically, deficits in cognitive control have also been shown in first-degree relatives of individuals with schizophrenia. MacDonald et al (2003b) used the expectancy version of the AX-CPT task to show a specific deficit in context processing that was associated with genetic liability. Specifically, they found that patients and siblings performed better on $\mathrm{AY}$ relative to $\mathrm{BX}$ trials, which implied worse context processing, compared with controls who performed better on BX relative to AY trials. A follow-up study utilizing the expectancy variant of the AX-CPT revealed significantly greater BX errors in siblings as well as increased activity throughout the cognitive control network compared with controls (Delawalla et al, 2008). Other measures of cognitive control, such as the Stroop (Filbey et al, 2008) and antisaccade task (Calkins et al, 2004), have also been shown to be associated with genetic liability. Becker et al (2008) used fMRI to evaluate relatives' performance and neural activity on a single-trial version of the Stroop task. Although behavioral performance was similar for relatives and controls, relatives showed increased activity in right dorsal and ventral PFC and left parietal cortex, as well as significantly decreased activity in the left dorsal PFC. In contrast, Thermenos et al (2004) showed increased activity in the left DLPFC in relatives compared with controls on the Q3A-INT task, which is a variant of the AX-CPT, in which subjects maintained the context of an auditory cue while being presented with distracting auditory information.

Converging evidence from structural neuroimaging studies also highlights the association between reduced gray matter volume and density in the PFC and genetic liability. Specifically, gray matter volume reductions have been noted in the DLPFC (Diwadkar et al, 2006) and anterior cingulate cortex (Job et al, 2003), as well as decreased cortical thickness in the anterior cingulate (Goghari et al, 2007) in unaffected first-degree relatives. Cannon et al (2002) utilized a twin design to show significantly decreased prefrontal gray matter volume (including DLPFC and polar PFC) that was associated with increasing genetic risk for schizophrenia.

The search for predictors of the development of schizophrenia has revealed a similar set of cognitive, neurofunctional, and structural brain abnormalities in individuals at genetic high risk. Although few genetic high-risk studies have employed longitudinal follow-up designs, the development of psychosis in adulthood in the offspring of individuals with schizophrenia has been associated with impairment in cognitive control as measured by the Stroop task (Johnstone et al, 2002). In addition, lower gray matter density in the left inferior temporal gyrus, uncus, and right cerebellum was found over follow-up in individuals who subsequently developed schizophrenia (Job et al, 2005). Increased prefrontal cortical folding has also been associated with subsequent development of psychosis (Harris et al, 2004a, b, 2007), providing evidence that abnormal development of prefrontal gray matter may contribute to later illness onset. Functionally, increased 
parietal activation and reduced anterior cingulate activation was associated with the later development of schizophrenia in the Edinburgh High Risk sample (Whalley et al, 2004, 2006). These findings highlight the potential role of genes as a contributor to structural changes in prefrontal and parietal regions, which lead to observed deficits in cognitive control for both affected and unaffected risk groups.

\section{APPLYING PREFRONTAL ENDOPHENOTYPES TO THE GENETIC STUDY OF SCHIZOPHRENIA}

Family, twin, and adoption studies indicate that schizophrenia has a large genetic component, on the order of 6585\% (Cannon et al, 1998; Cardno et al, 1999; Kendler and Diehl, 1993; Sullivan et al, 2003). Given that transmission of the disorder has not been linked to a major gene, schizophrenia is generally thought to be associated with multiple genes of small effect, including both common variants and rare but highly penetrant copy number variants or CNVs (Karayiorgou and Gogos, 1997). Identification of the molecular genetic basis of the disorder has been challenging owing to this polygenic inheritance as well as to genetic heterogeneity and a non-trivial environmental component, which is show by incomplete concordance for schizophrenia in MZ co-twins (Cannon et al, 1998). In addition, the phenotypic presentation of the disorder is markedly heterogeneous, with varying expression of core features of positive, negative, and cognitive symptoms. Given the phenotypic and genetic complexity of schizophrenia, the utilization of neural and cognitive endophenotypes may offer additional power to detect susceptibility loci by examining traits closer to the mechanism of abnormal gene action. In addition, the quantitative nature of these data allows for examination of the trait in unaffected relatives, as well as offering greater resolution in mapping genes of small effect. Although the use of cognitive or neuroimaging endophenotypes has often been highlighted as a way to facilitate the identification of genes associated with the pathophysiology of schizophrenia, the identification of functional variants remains, to date, somewhat elusive. Therefore, we will discuss current findings on two potential genetic linkages that have shown consistent relationships with prefrontally mediated cognition.

Two genes, DTNBP1 (ie, dysbindin) and catechol-omethyltransferase (COMT), have arguably garnered the most support as potential contributors to impaired PFC cognition in schizophrenia (for a review, see Joyce and Roiser, 2007). Dysbindin codes for a protein that is expressed within the forebrain glutamatergic neurons and interacts with proteins involved in vesicular transport and glutamate release. Using a mouse model, Jentsch et al (2009) showed that mice carrying a null mutation in the $d y s b i n d i n$ gene showed impairments of spatial working memory in a gene dose-dependent manner. These data provide support for a putative mechanism for prefrontal dysfunction in schizophrenia, suggesting that altered regulation of glutamatergic circuits in the PFC may play a role in the cognitive phenotype of the disorder. Generally, the dysbindin high-risk haplotype has been associated with cognitive decline, as measured by a decrease in IQ of 10 points (Burdick et al, 2007), although the dysbindin genotype only accounted for $2.2 \%$ of the variance in cognitive decline. Donohoe et al (2007) found lower spatial working memory performance in patients carrying the dysbindin risk haplotype, in which the dysbindin haplotype explained $12 \%$ of the variation in working memory performance. In agreement with animal studies mentioned previously (Jentsch et al, 2009), dysbindin has been associated with altered activation within the DLPFC during working memory (Markov et al, 2010). Specifically, the authors found that healthy subjects who carried the risk allele showed greater activation in DLPFC compared with noncarriers. In patients with schizophrenia, the high-risk allele has been associated with reduced gray matter volume in the PFC (Donohoe et al, 2010).

COMT is an enzyme involved in synaptic dopamine (DA) catabolism that has an important role in the PFC, in which there are relatively fewer DA transporters (Sesack et al, 1998). The majority of studies investigating cognitive performance and COMT have focused on the val ${ }^{158}$ met polymorphism (for a recent review, see Tan et al, 2009). In patients with schizophrenia, loading of the COMT met allele conferred enhanced cognitive performance on the Wisconsin Card Sorting Test, a measure of executive function, and a more efficient physiological response in the PFC during an $\mathrm{N}$-back working memory task (Egan et al, 2001b). Other complementary studies identified an association between the val allele and impaired performance on working memory (Wirgenes et al, 2010; Woodward et al, 2007) and attention (Bilder et al, 2002). However, others have either been unable to replicate these findings (Ho et al, 2005; Szoke et al, 2006) or have even found incongruent results. For example, Neuhaus et al (2009) found that poor performance on the signal discrimination index of the CPTIP was associated with the met variant in a gene dosedependent manner. The presence of the all $^{158}$ met genotype in patients has also been associated with opposite effects in brain activation compared with controls, such that control subjects with the homozygous met genotype showed greater activity on a verbal fluency task in the frontal operculum, parietal operculum, and middle temporal gyrus than those with the homozygous val genotype (Prata et al, 2009). These findings were reversed for the patient group, such that patients with the homozygous met genotype showed less activity in these regions compared with patients with the homozygous val genotype. Moreover, a similar genotype by group interaction was found on behavioral performance measures, as the loading of the met allele in patients and the val allele in controls was associated with better performance. These data have prompted the development of an altered efficiency model, which posits that loading of the met allele in patients, and higher availability of DA in the PFC, is associated with better performance, 
whereas loading of the met allele in healthy subjects may push DA availability and cortical function beyond the optimal range. Such a discrepancy between healthy controls and patients was also illustrated in a meta-analysis of COMT genotype and WCST performance, in which genotype was associated with perseverative errors in healthy controls but not in patients with schizophrenia (Barnett et al, 2007). Although there is evidence for an association with COMT and prefrontally biased cognition, the effect on risk for schizophrenia is small and inconsistent based on recent meta-analyses (Allen et al, 2008; Fan et al, 2005; Munafo et al, 2005; Okochi et al, 2009).

In addition to COMT and dysbindin, a number of other candidate genes have been identified by linkage and targeted association studies, including neuregulin 1 (NRG1), disrupted in schizophrenia 1 , and $d$-amino-acid oxidase. NRG1 in particular codes for a trophic factor with a range of functions that includes the modulation of $\gamma$-aminobutyric acid (GABA)-ergic transmission, which is critical for PFCmediated cognition and will be described in greater detail later in the review (Mei and Xiong, 2008).

Although a comprehensive analysis of this literature is outside the scope of this review (for a review, see Eisenberg and Berman, 2010), it is important to note that there is substantial disagreement as to how to interpret the existing genetic association data (O'Donovan et al, 2009). Some researchers may place more emphasis on genes with more modest empirical support but with strong pathophysiological relevance to the disorder, whereas others may be more agnostic to the mechanism of gene action and primarily concerned with a strong, reliable association. Although the candidate genes mentioned above all have putatively strong pathophysiological mechanisms relevant to schizophrenia, given that they impinge upon prefrontal systems, none of the genes yet identified remain unchallenged and all await further study. Moreover, our ability to elucidate the genetic underpinnings of the disorder may increase as genetic association studies move towards tasks generated from the cognitive neuroscience literature that tap specific cognitive control processes.

\section{EVIDENCE FOR COGNITIVE CONTROL DEFICITS IN CLINICAL HIGH RISK}

Although most individuals with schizophrenia experience the onset of clinical symptoms during late adolescence and early adulthood, deficits in cognition are evident years before the development of psychotic symptoms, during childhood and adolescence (Cannon et al, 2000a; Cornblatt et al, 1999; Erlenmeyer-Kimling et al, 2000; Jones et al, 1994; Niendam et al, 2003; Russell et al, 1997). These cognitive deficits are hypothesized to accelerate during the prodromal period in association with changes in brain functioning that lead to the development of psychotic symptoms (Feinberg, 1982; McGlashan and Hoffman, 2000). Such neurological changes may also lead to functional decline in a variety of domains (Cosway et al, 2000). Therefore, deficits in cognition in high-risk samples not only serve as markers of risk, but changes in such deficits over time may differentiate those individuals who convert to psychosis or experience functional disability from those who do not.

Impairment in multiple cognitive domains are reported in clinical high risk (CHR) samples (McGlashan, 2001; Miller et al, 2002), with the most pronounced deficits observed on measures of frontal and temporal lobe functions, including attention, working memory, processing speed, executive functioning, and verbal learning and memory (Bartok et al, 2005; Brewer et al, 2005; Eastvold et al, 2007; Francey et al, 2005; Gschwandtner et al, 2003, 2006; Hambrecht et al, 2002; Hawkins et al, 2004; Keefe et al, 2006; Lencz et al, 2006; Niendam et al, 2006, 2007; Pukrop et al, 2007, 2006; Silverstein et al, 2006; Simon et al, 2007; Smith et al, 2006; Wood et al, 2003b). Evidence of impairment on computerized measures of prefrontal cognitive functioning in CHR youth when compared with normal controls has also been reported (Francey et al, 2005; Gschwandtner et al, 2003, 2006; Hambrecht et al, 2002; Hawkins et al, 2004; Keefe et al, 2006; Lencz et al, 2006), although CHR individuals showed better performance than individuals with first-episode schizophrenia (Hambrecht et al, 2002; Hawkins et al, 2004; Keefe et al, 2006). Overall, impairments on measures of prefrontal cognitive functioning, including spatial working memory (Wood et al, 2003b), antisaccade eye movements (Nieman et al, 2007), olfactory identification (Brewer et al, 2003), and rapid information processing (Brewer et al, 2005; Lencz et al, 2006), are associated with conversion to psychosis.

When compared with healthy controls, CHR individuals also show a variety of structural and functional abnormalities, including reduced gray matter density in frontal, temporal, and subcortical brain regions (Borgwardt et al, 2007b; Hurlemann et al, 2008; Jung et al, 2009; Phillips et al, 2002; Witthaus et al, 2008; Wood et al, 2005), as well as reduced $\mathrm{N}$-acetylaspartate (NAA) in frontal regions (Jessen et al, 2006; Wood et al, 2003a). The frequency of neurodevelopmentally associated abnormalities was also higher in CHR samples when compared with healthy controls (Choi et al, 2008; Takahashi et al, 2008a, b; Yucel et al, 2003).

Few neuroimaging studies focused on frontal functioning in CHR samples have been published to date. Morey et al (2005) examined frontal and striatal functions during a visual oddball paradigm in CHR, first episode, chronic schizophrenia, and healthy control samples. Behaviorally, the CHR individuals' performance was intermediate between the healthy control and first episode samples. In addition, the CHR group showed significantly smaller differential activation between task-relevant and taskirrelevant stimuli in the frontal regions (ACC, inferior frontal gyrus, middle frontal gyrus) than the control group. Similarly, CHR individuals have shown intermediate activation relative to controls and schizophrenia patients during a working memory task (N-back) in the DLPFC, inferior frontal, and parietal cortices (Broome et al, 2009). 
Fusar-Poli et al (2010) replicated this finding of reduced DLPFC and parietal activation in response to the N-back in combination with fluorine 18-labeled fluorodopa PET. The authors revealed that, within the at-risk group, the degree of abnormality in the PFC (ie, attenuated DLPFC activation) was associated with the severity of striatal DA dysfunction (ie, elevated Ki value). This relationship was reversed in the control group, such that prefrontal activation during working memory was positively correlated with the level of striatal DA function. This pattern of results was presented as evidence of an inverted $U$ relationship compatible with models of working memory that suggest there is an optimal level of DA activity associated with maximal efficiency of working memory performance (Williams and Castner, 2006). Taken together, these studies show that CHR individuals have difficulty activating the cortical network that underlies effective cognitive control processes and provide important evidence supporting the potential role of abnormalities in this network as a marker of risk for psychosis.

A recent review of this literature by Wood et al (2008) noted that impairments in prefrontal cognitive functioning, and the underlying neurobiological abnormalities, provide the most likely marker of conversion risk. In CHR samples, conversion to psychosis was associated with reduced gray matter density in frontal, temporal, and parietal regions (Borgwardt et al, 2007a, b, 2008; Fornito et al, 2008; Pantelis et al, 2003, 2005), although such findings were not consistent for analyses of the hippocampus (Phillips et al, 2002). Reductions in NAA in the anterior cingulate cortex (Jessen et al, 2006), thickness of the anterior genu of the corpus callosum (Walterfang et al, 2008b), and reduced serotonin receptor density in frontotemporal gray matter (Hurlemann et al, 2008) were also associated with conversion. Frontal white matter tracts, specifically the fronto-occipital fasciculus and left superior longitudinal fasciculus, were also reduced in size for CHR individuals who subsequently developed psychosis (Walterfang et al, 2008a). Taken together, these findings suggest that investigations of frontally mediated cognitive functions through functional neuroimaging hold the most promise as markers of risk for clinical, and potentially functional, deterioration in at-risk samples.

\section{IMPLICATIONS OF HIGHER COGNITIVE DYSFUNCTION AND THE DEVELOPMENTAL PATHWAY PRECEDING SCHIZOPHRENIA}

As noted above, cognitive deficits are present at the onset of the psychotic phase of the illness, during the prodromal phase, and even in those at risk for the illness. Consequently, schizophrenia has been conceptualized as a neurodevelopmental disorder in which genetic and environmental etiological factors affect processes related to brain development that in turn result in the clinical expression of the disorder during adolescence, itself a time of rapid brain development. According to the neurodevelopmental hypothesis of schizophrenia originally proposed by Feinberg (1982), abnormal pruning of synaptic connections in the cortex during adolescence leads to the onset of psychotic symptoms. In normal development, the pruning of superfluous synaptic connections during normal brain development results in increased efficiency and specialization of cortical and subcortical areas; however, in schizophrenia it is hypothesized that environmental stress and/or genetic liability could alter the pruning process and cause an abnormal rate or pattern of synaptic elimination, resulting in the development of psychotic symptoms.

Using a computer simulation of the pruning process, McGlashan and Hoffman (2000) showed how the pruning of connections above a particular threshold resulted in cognitive impairment as well as the appearance of 'hallucinations' during tasks of speech perception. In their model, the pruning process can advance at varying levels of intensity, with the most aggressive pruning leading to the earliest onset of psychosis and reduced opportunity for later recovery. Conversely, by decreasing the baseline level of available connections, it was shown that early brain insult could reduce the neuronal reserve, in which case a normal pruning process would be sufficient to cross the threshold into psychotic symptoms. Therefore, early brain injury in the form of prenatal insult (eg, Brown and Derkits, 2010; Cannon et al, 2000c), postnatal environmental stress (eg, van Winkel et al, 2008), and/or abnormal rates of synaptic pruning during adolescence could work alone or in conjunction to push an individual past the threshold into psychosis.

Empirical evidence has accumulated to support this notion. In a post-mortem study of individuals with schizophrenia, Selemon et al (1995) showed abnormally high neuronal density in the prefrontal and occipital cortices. A previous hypothesis attributed decreased cortical gray matter volume to the effects of widespread neuronal cell death (Weinberger, 1987). However, Selemon and Goldman-Rakic (1999) associated the increased density of cells, in the context of reduced volume, with the loss of neuropil, or interconnections between the neurons, which could be the result of excessive pruning. Glantz and Lewis (2000) provided additional support for this hypothesis by showing decreased dendritic spine density in the layer 3 pyramidal neurons of the DLPFC. Therefore, whereas the process of synaptic pruning in normal development serves to increase the efficiency of brain functioning, the observed deficits in schizophrenia may be related to an overly aggressive pruning process that reduces neuronal interconnection to a detrimental level, leading to the development of psychotic symptoms and related cognitive dysfunction that may become manifest during the prodromal period. Alternatively, an initially depleted neuronal connectivity, which may be associated with early brain insult, could lead to symptoms of schizophrenia if subsequent normal pruning processes decrease that connectivity further, crossing a hypothetical threshold beyond which the capacity for integrated cognitive and emotional 
activity is severely compromised. Recently, Reichenberg et al (2010) used long-term follow-up data to examine cognitive development between the ages of 7 and 13 in the Dunedin birth cohort. Examination of cognitive variables revealed that individuals who later develop schizophrenia showed deficits in verbal and visual knowledge, comprehension and reasoning at age 7, as well as a slowing in the development of processing speed, working memory, and visual-spatial reasoning as they progress through puberty. These findings support an integrated model of aberrant cognitive development in schizophrenia, incorporating both a static cognitive deficit that is apparent early in childhood as well as a developmental lag in cognitive domains supporting attention and working memory as they grow through adolescence.

\section{THE ROLE OF MICRO- AND MACRO-CIRCUIT DYSFUNCTION IN IMPAIRED COGNITIVE CONTROL IN SCHIZOPHRENIA}

Given convergent findings from structural and functional neuroimaging studies, post-mortem data, and genetic association studies that implicate the PFC as a region associated with the cognitive deficits that characterize schizophrenia, a large body of work has led to a search for pathophysiological mechanisms associated with interneuron connectivity within the PFC (micro-circuits) as well as regional connectivity (macro-circuits). Sustained firing of pyramidal neurons within the DLPFC during engagement in a working memory task has been shown to be crucial to successful task performance (Goldman-Rakic, 1995; Wilson et al, 1994). Changes in local circuit function in the PFC may contribute to failure of this region to recruit task appropriate networks across the brain and lead to disorganized brain function and behavior in schizophrenia. Although such a hypothesis can only be directly tested at this time in animal models, functional neuroimaging findings of altered BOLD signal within DLPFC have generally been the closest proxy. Relevant to this, Logothetis and others (Logothetis et al, 2001; Murayama et al, 2010; Niessing et al, 2005) recorded directly from neuronal populations during fMRI to show that the BOLD signal is most strongly related to population neuronal activity, as reflected in field potentials, and specifically to synchronous neuronal activity in the high-frequency gamma $(30-80 \mathrm{~Hz})$ range. This is particularly significant in view of the results of post-mortem studies in schizophrenia. Reduced GABA release by the parvalbumin subclass of GABA-ergic interneurons in the PFC and other regions of the brain is suggested by a range of post-mortem findings reported across a number of laboratories (for a review, see GonzalezBurgos and Lewis, 2008; Lewis et al, 2005). Other studies, including those cited above, suggest that there is altered thalamocortical connectivity, including possibly decreased neuronal numbers in the thalamus as well as reduced dendritic spines on pyramidal cells in the thalamic recipient zones of Brodmann area (BA) 9. Projections from medial dorsal thalamus to DLPFC are critical for initiating and maintaining gamma band activity (Jones, 1997), whereas chandelier cells gate the timing of synchronous activation of populations of pyramidal neurons by targeting the axon initial segment of pyramidal cells through membrane receptors with fast spiking calcium channels. These postmortem disturbances would be predicted, in life, to be associated with impairments in prefrontal gamma activity and an associated reduction in cognition-related BOLD activity.

Oscillatory activity in the gamma range is readily recorded from the human EEG and there has been increasing interest in both normal cognitive neuroscience and in the study of schizophrenia in recent years. Oscillatory activity can be evoked or induced (Galambos, 1992). Evoked gamma responses are temporally locked to stimuli and typically thought to reflect perceptual processes; induced gamma band responses represent signals independent of evoked ones, typically appearing later during a trial of a task, with a jittered latency across trials, and are thought to be associated primarily with higher cognitive processes (for a review, see Tallon-Baudry and Bertrand, 1999a). For example, in studies of visual working memory, many investigators (Howard et al, 2003; Tallon-Baudry and Bertrand, 1999a; Tallon-Baudry et al, 1998, 1999b) have reported induced gamma band responses over frontal leads during delay periods of working memory tasks. Although these data are often interpreted as being related to the maintenance of information in working memory, a substantial literature in cognitive neuroscience suggests that the DLPFC maintains context representation during working memory tasks, in support of task appropriate responding (Miller and Cohen, 2001) based on items stored in ventral PFC and posterior areas. This raises the possibility that alterations in PFC gamma band oscillatory functions related to forming and maintaining a context representation might be impaired in schizophrenia and related to impaired cognitive control. Disturbances in local micro-circuits in the PFC and an inability to generate sustained oscillatory activity in this region may form the basis for disrupted top-down support to task-relevant circuits across the brain at a macro-circuit level, leading to impaired task-related cognitive activity and behavioral disorganization in the illness. Cho et al (2006) reported a reduction in PFC-related gamma activity in schizophrenia during cognitive control, a finding that was also related to impaired task performance and behavioral disorganization in the patient group. Figure 3 summarizes an integrated model in which altered local micro-circuit function disrupts high-frequency oscillations in the PFC, leading to a failure of top-down support for the recruitment of task appropriate macro-circuits or distributed networks in the brain, resulting in impaired task appropriate behavior, clinical disorganization, and impaired functioning in schizophrenia. This model integrates decades of research that has focused on DLPFC dysfunction in schizophrenia, while providing detailed links between cellular mechanisms, altered neurophysiology, and the clinical phenotype of 


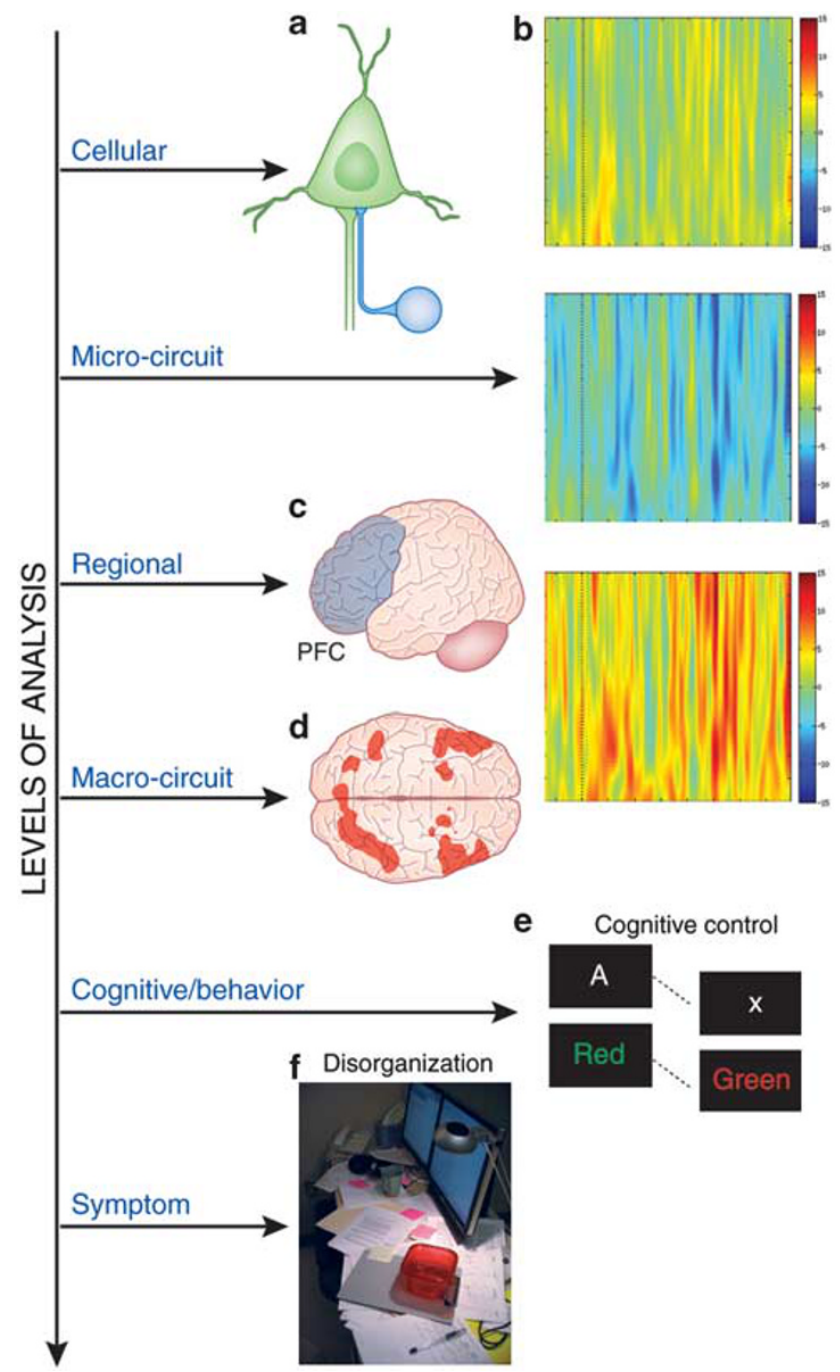

Figure 3. From cells to circumstantiality: a unified model outlining (a) $\gamma$-aminobutyric acid (GABA)-ergic cellular abnormalities, (b) 'microcircuit' gamma oscillatory function, (c) regional recruitment of the prefrontal cortex (PFC) in mediating cognitive control, (d) engagement of the 'macro-circuit', the coordinated activation of frontal and parietal regions as a neural system, (e) cognitive/behavioral performance on cognitive control tasks (eg, AX-Continuous Performance Task (AX-CPT) and Stroop), and (f) disorganization symptoms.

schizophrenia. This specific pathophysiological conceptualization can help guide future genetic studies by providing specific cognitive and neural endophenotypes. In addition, this model has the potential of enhancing the identification and development of novel treatment targets, such as partial agonists at the $\alpha_{2}$-subunit of the GABA-A receptor (Lewis et al, 2008a), as well as aiding the development of new biomarkers for use in the future for diagnosis and risk identification.

\section{IMPLICATIONS FOR PHARMACOLOGY OF HIGHER COGNITION IN SCHIZOPHRENIA}

Current consensus supports cognitive dysfunction as a critical treatment target in schizophrenia. The FDA has recently agreed to consider cognitive dysfunction as a discrete indication for approval of new pharmacological agents in schizophrenia (Buchanan et al, 2005). Among the existing FDA-approved pharmacopoeia, considerable recent research has addressed the potential of atypical antipsychotic medication for remediation of cognitive dysfunction. It has been proposed that this advantage may arise from unique pharmacological actions of the atypical antipsychotics as these medications elevate catecholamines and glutamate in the cortex, particularly the PFC (Meltzer and Huang, 2008; Stip et al, 2005). These effects would likely be owing to direct antagonism of serotonergic and adrenergic receptors, which are located on catecholamine and glutamatergic terminals, and serve to inhibit neurotransmitter release. Nonetheless, the clinical literature addressing effects of atypical antipsychotics on cognition in schizophrenia is plagued by several important methodological problems (Goldberg et al, 2007); (Carpenter and Gold, 2002; Carter, 2005; Harvey and Keefe, 2001; Montgomery et al, 2004; Weiss et al, 2002), contributing to considerable heterogeneity in existing findings with regard to the effects of these medications on cognition. As a result, there is an emerging consensus that there is no strong evidence for atypical antipsychotic remediation of cognition in schizophrenia and there remains a great need to identify and develop truly novel agents for this indication.

Several neurotransmitter systems in the brain have critical roles in supporting the neural networks believed to be impaired in schizophrenia, including the PFC, and offer potential treatment targets for cognition. Perhaps, the most well established are the two primary catecholamine systems, DA and norepinephrine (NE). The DA hypothesis of schizophrenia has been an enduring framework for investigation of the pathophysiology of this illness, and recent evidence has elaborated the role of this neurotransmitter system (Carlsson and Carlsson, 2006). Seamans and Yang (2004) outlined an elegant theory of DA modulatory function in the PFC, such that breadth and salience of information in working memory is controlled by DA PFC inputs. This model has relevance to schizophrenia as a chronic state of hypodopaminergia has been implicated in the PFC of schizophrenia patients, with decreased tyrosine hydroxylase binding (Akil et al, 1999) and increased D1 binding, which may represent a compensatory upregulation in response to a chronic deficit of synaptic DA (AbiDargham et al, 2002). This could contribute to PFCdependent cognitive deficits, as research shows that 6-OHDA lesions in the DLPFC disrupt working memory in monkeys (Brozoski et al, 1979). The D1 receptor appears critical in delineating PFC DA effects, as microinjection of D1 antagonists (but not D2 antagonists) into the DLPFC disrupts working memory-guided saccades (Sawaguchi and Goldman-Rakic, 1994). In studies of healthy adult humans as well as patients with schizophrenia, amphetamine improves working memory (Barch and Carter, 2005), with associated changes in DLPFC activity measured by fMRI (Mattay et al, 2000). The D1/D2 agonist pergolide shows 
specific benefits for working memory, in contrast to other cognitive functions (Kimberg and D'Esposito, 2003). D1 receptors also modulate both long-term potentiation and long-term depression in the rodent PFC, probably through interactions with NMDA receptors, providing a cellular mechanism for DA effects on PFC plasticity (Jay, 2003; Otani et al, 2003). Chronic treatment of monkeys with typical or atypical antipsychotics (at clinically relevant doses) also leads to spatial working memory deficits (Castner et al, 2000), along with D1 receptor downregulation in PFC (Lidow et al, 1997). The potential exacerbation of pre-existing DA dysfunction could partly explain the lack of efficacy of existing medications for PFC-dependent cognition in schizophrenia. D4 receptors have also been targeted in schizophrenia. However, D4 antagonists do not appear to have efficacy for the symptoms of schizophrenia, and enhancements in working and episodic memory have been observed in animal models after both D4 agonists and antagonists, suggesting that the role of D4 receptor in cognition is complex and possibly multiphasic (Gray and Roth, 2007).

The ascending NE system is also implicated in PFCdependent cognition. This relates in part to the observation that the NE transporter (NET) is largely responsible for the termination of DA action in the PFC, owing to a paucity of DA transporter protein (Moron et al, 2002). However, NE itself strongly modulates PFC neurons and associated cognitive processes. For instance, $\alpha_{2}$-receptor agonists improve working memory performance in monkeys when administered either systemically or directly into the PFC (Franowicz and Arnsten, 1998). Clonidine reverses the working memory deficit induced in rats by PCP (Marrs et al, 2005). $\alpha_{2}$-Receptor antagonists can reverse the benefit of $\alpha_{2}$-agonists when co-administered, and impair memory performance when given alone ( $\mathrm{Li}$ and Mei, 1994). These effects appear to occur at post-synaptic sites. Guanfacine also improves spatial working memory in healthy humans (Jakala et al, 1999). Furthermore, there is considerable evidence for NE modulation of plasticity-dependent processes, such as long-term memory consolidation, via $\beta$-adrenergic receptors in PFC and elsewhere (Tronel et al, 2004).

To date, agents that have adequate brain penetration and direct agonist activity at specific catecholamine receptor subtypes remain generally unavailable to test this mechanism for remediation of cognition in schizophrenia. However, a number of catecholamine transporter inhibitors are in use for other neuropsychiatric indications, particularly for attention-deficit disorder. Among these, there is evidence that low-dose amphetamine improves PFC-dependent cognitive function in schizophrenia (Barch and Carter, 2005; Daniel et al, 1991), and more recent evidence that modafinil improves PFC-dependent cognition in schizophrenia patients (Turner et al, 2004; for a review, see Minzenberg and Carter, 2008a), which may be a function of modulation of locus coeruleus neuronal activity (Minzenberg et al, 2008b). In addition, a small study found atomoxetine to improve working memory-related PFC activity in schizophrenia (Friedman et al, 2008), and inhibition of COMT with tolcapone improves cortical activity and working memory performance in healthy adults, dependent on COMT genotype (Apud et al, 2007). This evidence, while preliminary, suggests that the modulation of catecholamine neuronal activity, and augmentation of these neurotransmitters in the cortex, may be a safe and effective therapeutic strategy for cognition in schizophrenia.

More recently, neurons that use GABA as a neurotransmitter have become a major focus for models of pathophysiology in schizophrenia (Gonzalez-Burgos and Lewis, 2008). Post-mortem studies have found consistent evidence of reduced mRNA for the $67-\mathrm{kDa}$ isoform of the enzyme that synthesizes GABA, glutamic acid decarboxylase (GAD-67), as well as reduced mRNA coding for the GABA membrane transporter (GAT1). These changes are both observed in the DLPFC in a subpopulation of GABA-ergic neurons that express the calcium-binding protein parvalbumin (Gonzalez-Burgos and Lewis, 2008). These fastspiking interneurons exert a strong influence on the timing of cortical pyramidal cell activity as well as subthreshold membrane potentials in these cells, and are major determinants of high-frequency cortical oscillations, such as those in the gamma range $(30-80 \mathrm{~Hz})$. As described previously, gamma oscillations are associated with a range of higher-order cognitive processes, and are consistently impaired in schizophrenia. Interestingly, a recent study found that a partial agonist at the $\alpha_{2}$-subunit of the GABA-A receptor remediates this oscillatory deficit in schizophrenia (Lewis et al, 2008a). The predominant medications currently available that act at the GABA-A receptor are the benzodiazepines, which lack pharmacological or anatomical specificity, and probably disrupt the finely tuned temporal dynamics of GABA-ergic (and thus pyramidal cell) activity. In contrast, agents that inhibit GAT1 (eg, tiagabine), for instance, may augment neurotransmission at GABA synapses while largely preserving the temporal pattern of signaling that is necessary to establish or maintain cortical oscillations. These remain to be studied for effects on cognition in schizophrenia.

Glutamate is another neurotransmitter that has been considered as a potential target for cognitive remediation in schizophrenia. There is evidence of impaired glutamatergic function in schizophrenia (Coyle, 2006), including impaired plasticity processes (Lewis and Gonzalez-Burgos, 2008b), and the clinical and biological effects of non-competitive NMDA receptor antagonists (such as ketamine and phencyclidine) suggest a role in the treatment of cognitive impairment in schizophrenia. Accordingly, enhancement of NMDA receptor function has been an emerging line of research, particularly targeting the glycine modulatory site on the NMDAR. Although initial small pilot studies suggested clinical improvement with the administration of glycine, D-serine and D-alanine, a large multi-center study found no effects on MATRICS neuropsychological measures among schizophrenia patients treated with glycine or 
D-cycloserine (Buchanan et al, 2007). Glycine transporter inhibitors that have shown promise in pre-clinical studies, however, have not been tested to date for effects on cognition in schizophrenia patients. Allosteric potentiators of AMPA receptor function (AMPAkines) also improve cognition in animal models; however, a large multi-center study failed to show cognitive benefits with the AMPAkine CX-516 added on to existing atypical antipsychotic treatment (Goff et al, 2008). A study of a new agonist at the metabotropic 2/3 subtype glutamate receptor has shown promise for symptoms of schizophrenia in a phase II clinical trial; however, it remains unknown whether this is accompanied by cognitive improvement (Patil et al, 2007).

The central cholinergic system has also been targeted for cognitive remediation in schizophrenia. Earlier work focused on acetylcholinesterase inhibition as a mechanism to enhance synaptic acetylcholine. Although an initial pilot study showed enhanced PFC activity in schizophrenia patients on donepezil (Nahas et al, 2003), repeated clinical trials of AChE inhibitors failed to show improvements in cognition (Ferreri et al, 2006). More recently, direct nicotinic receptor agents have been tested, with an emphasis on the $\alpha 7$-subunit of the nicotinic receptor. A partial agonist drug with selectivity for the $\alpha 7$-subunit (DMXB-A) initially showed promise for cognition, with single-dose benefits on the RBANS summary score (Olincy et al, 2006); however, a larger phase 2 trial generally failed to show improvement in the MATRICS neuropsychological battery (Freedman et al, 2008). It remains unclear whether this is owing to tachyphylaxis of the nicotinic receptor in response to sustained exposure to the drug, inadequacy of the cognitive measures, some aspect of the clinical sample, or other issues. Muscarinic ACh receptors have been investigated as well. The antimuscarinic activity of the antiparkinsonian agents, as well as intrinsic antimuscarinic activity found in medications such as olanzapine, appears to exacerbate cognitive dysfunction in schizophrenia (Minzenberg et al, 2004; Vinogradov et al, 2009). More specifically, the M1 receptor subtype has been implicated in schizophrenia post-mortem studies (Crook et al, 2000, 2001), M1 receptor knockout mice exhibit working and long-term memory deficits (Anagnostaras et al, 2003), and this receptor strongly modulates cortical gamma oscillatory activity (Whittington et al, 2000). Although a major clozapine metabolite (NMDC) appears to be a potent M1 agonist (Sur et al, 2003), there is no available agent yet with sufficient selectivity for this receptor to provide an adequate test of M1 agonism in cognitive remediation.

The role of the central histaminergic (HA) neurotransmitter system in systems neuroscience and cognition has been elaborated recently. The major focus has been on the recently discovered $\mathrm{H} 3$ receptor, which acts as both an autoreceptor on histaminergic terminals, but importantly also as an inhibitory heteroreceptor on the terminals of several other neurochemically defined cell types (Esbenshade et al, 2006). These include catecholamines, and cholinergic and serotonin neurons. The central HA system serves an information-processing role quite similar to that of the cholinergic system, directly modulating various forms of attention and memory. Non-selective antihistamine medications that penetrate the brain are well known to impair a range of cognitive processes, and antagonism of the $\mathrm{H} 3$ terminal autoreceptor could improve cognition in part by enhancing synaptic HA. In addition, however, the indirect effects of HA antagonism (or $\mathrm{H} 3$ gene knockout) at the $\mathrm{H} 3$ terminal heteroreceptor serve to amplify catecholamine and cholinergic modulatory effects on cortical function. This includes PFC function subserving working and long-term memory, attention, and executive functions (Esbenshade et al, 2006). Although it remains unknown whether there is any underlying disturbance in the HA system in schizophrenia, these HA modulatory effects on other transmitter systems and cortical function suggest a very novel target with a potentially excellent costbenefit profile in clinical terms. Accordingly, several pharmaceutical firms have $\mathrm{H} 3$ antagonists in development for cognition in schizophrenia.

Finally, the endocannibinoid system has been implicated in schizophrenia, and may serve as a highly novel treatment target for both cognitive and clinical symptomatology. Epidemiological studies indicate a strong association of high levels of cannabis use and psychosis (Henquet et al, 2008), and acute intoxication can produce symptoms (D'Souza et al, 2004). There is also evidence of alterations in this system in schizophrenia, such as increased binding at the $\mathrm{CB} 1$ receptor, the primary cannabinoid receptor in the brain (Dean et al, 2001; Newell et al, 2006; Zavitsanou et al, 2004), and increased CSF levels of anandamide, the primary endogenous ligand in the brain (Giuffrida et al, 2004; Leweke et al, 1999), in schizophrenia patients. Variation in the CNR1 gene (which codes for the CB1 receptor) is associated with both risk for schizophrenia (Ujike et al, 2002) and variation in clinical response to atypical antipsychotics (Hamdani et al, 2008). CB1 receptors function primarily to mediate retrograde signals from post-synaptic to pre-synaptic neurons and, via this mechanism, influence a range of plasticity processes (Heifets and Castillo, 2009; Lovinger, 2008). The cell types regulated by $\mathrm{CB} 1$ receptors include $\mathrm{DA}$, glutamate, and GABA. In animal models of cognition, CB1-active agents modify various forms of memory, with antagonists remediating the adverse effects of endogenous or exogenous CB1 agonists to normalize cognition (Egerton et al, 2006). This suggests that $\mathrm{CB} 1$ antagonists may remediate the cognitive deficits inherent to schizophrenia, the adverse effects of cannabis use on cognition and clinical state, or even modify a major risk factor for the onset of this illness. Rimonabant is a CB1 antagonist that was initially tested to treat cardiovascular risk factors associated with obesity, but was withdrawn owing to safety concerns. However, this class of agents remains of interest for various clinical indications in medicine, and a test of their potential for cognitive and clinical remediation in schizophrenia is warranted. 


\section{PFC-BASED COGNITIVE CONTROL AS A TREATMENT TARGET IN SCHIZOPHRENIA}

As observed above, there are varied effects of pharmacological intervention on PFC function and the range of cognitive processes supported by the PFC. This heterogeneity may arise from the diverse roles of different neurotransmitter systems in the support of these processes, and from numerous methodological factors in the existing empirical literature in both animal models and in clinical trials. Nonetheless, the construct of cognitive control may offer an integrative framework to specify a novel target for treatment development.

This warrants the consideration of pharmacology studies that use explicit cognitive control measures. This is a small literature to date and the majority of studies focused on catecholamine systems. Single-dose $d$-amphetamine (d-AMP) $0.25 \mathrm{mg} / \mathrm{kg}$ orally has been found to enhance speed on a classic Stroop task, both in healthy subjects and in stable schizophrenia patients (Barch and Carter, 2005), and improved accuracy in healthy subjects on the conflict condition of the Eriksen Flanker task (Servan-Schreiber et al, 1998). A study of healthy subjects using a lateralized version of the classic Stroop found bromocriptine to modestly improve conflict-related RT, whereas pergolide (a mixed D1/D2 agonist) was ineffective (Roesch-Ely et al, 2005). These findings suggest that D2 receptors may mediate the major effect of DA on control processes, possibly by modulating the rate or pattern of DA cell firing via the cell-body D2 autoreceptor. Using the AX-CPT task, a 4-week double-blind course of treatment of schizotypal personality disorder subjects with guanfacine, a specific $\alpha-2$ adrenergic agonist, was associated with improved performance, as BX errors were significantly reduced and AY errors were more modestly increased, a pattern approaching that of healthy subjects (McClure et al, 2007). In contrast, a parenteral dose of $d$-AMP administered to rats $(0.5 \mathrm{mg} / \mathrm{kg}$ subcutaneously) led to increased BX errors (but not AY errors) on an AX-CPT analog task (Maes et al, 2001). This may occur at higher AMP doses that push subjects to the descending limb of an inverted-U curve relating cognition to neurotransmission. Studies using electrophysiology during Flanker performance by healthy subjects have found haloperidol to attenuate both performance and the errorrelated negativity (ERN) (Zirnheld et al, 2004), whereas yohimbine augmented both the performance and the ERN (Riba et al, 2005). As an $\alpha-2$ antagonist, yohimbine may have exerted its major effect either at the cell body, to increase action potential activity (potentially in a taskrelated manner), and/or to augment $\mathrm{NE}$ release by inhibiting the terminal autoreceptor. The effect of modafinil, a mixed DAT/NET inhibitor, on neural activity measured by fMRI during cognitive control performance suggests that modulation of LC cell-body activity may be a strong determinant of PFC-based control processes (Minzenberg et al, 2008b). The role of DA in performance monitoring, specifically in modulating the ERN (Holroyd and Coles, 2002) is proposed to arise from the reward prediction error. This is observed in reinforcement learning paradigms and mediated by a transient decrease in midbrain DA cell firing in response to errors or negative feedback (Schultz et al, 1997), disinhibiting pyramidal cells in the ACC as one result. Although this model remains to be adequately tested, it does provide a useful heuristic to guide pharmacological studies.

The role of other neurotransmitter systems in modulating cognitive control processes has been much less well studied. A few studies have found that decreased serotonin activity during Stroop performance (achieved by orally induced transient depletion of tryoptophan, a precursor to serotonin) is associated with increased neural activity in ACC and DLPFC (Horacek et al, 2005) and improved performance (Scholes et al, 2007). Given the opponent interactions between DA and serotonin (Daw et al, 2002), probably mediated primarily via inhibitory serotonin (5-HT2) receptors on DA neurons, an advantageous feature of candidate pro-control agents for schizophrenia may combine pro-catecholamine and serotonin antagonist activity, analogous to the combination of DA antagonist and serotonin antagonist activity for the symptomatology of schizophrenia. Another important consideration arising from this relatively small but provocative literature is that agents that alter the firing patterns of monoamine cells may have a unique potential, compared with direct post-synaptic receptor-active agents, in modulating these systems and their effects on the distributed cortical-subcortical networks that support complex cognitive processes. The potential of other neurotransmitter systems as targets to enhance cognitive control processes awaits further basic science research, both in animal models and in humans.

\section{ALTERNATIVE MODELS FOR HIGHER COGNITIVE DEFICITS IN SCHIZOPHRENIA}

Although the cognitive control model we propose here seeks to unify a number of discrete findings of deficits within the domain of higher cognitive dysfunction in schizophrenia, several alternative views have been articulated. One such view is that the range of cognitive deficits noted in schizophrenia, in fact, represents multiple distinct impairments that are each linked to individual neural systems that together produce the syndrome. In this 'multiple endophenotype' view, cognitive control processes would simply represent one of the many discrete deficits that compose schizophrenia. This view is reinforced by findings that particular morphometric features (eg, hippocampal size) and cognitive performance (eg, verbal declarative memory) may be associated with increasing genetic liability to the disorder (for a review, see Cannon and Keller, 2006; van Erp et al, 2004). As mentioned previously, other candidate cognitive endophenotypes have been proposed and investigated, including early sensory processing (eg, mismatch negativity, prepulse inhibition), executive dysfunction, and language dysfunction (Bertisch et al, 2010; Braff and Light, 2005; Calkins et al, 2004; Freedman et al, 2003; 
Glahn et al, 2003; Gottesman and Gould, 2003; Hasenkamp et al, 2010; Winterer et al, 2003). The 'multiple endophenotype' approach has developed and maintained strength owing to the idea that each specific cognitive endophenotype may be more tightly linked to a particular functional gene that may be causal for schizophrenia. However, this drive toward cognitive and genetic specificity may have narrowed our focus too sharply and led the field away from a broader, more integrative perspective. Just as some medical illnesses can manifest with a variety of disparate physical symptoms (eg, systemic lupus erythematosis), a piecemeal approach to cognition in schizophrenia may obscure the fact that the failure of a singular overarching cognitive domain could yield a substantial proportion of the varied pattern of cognitive deficits that are observed in the disorder. Future investigations should systematically investigate the interplay between diverse cognitive systems to address the question as to whether impairment in one overarching domain, such as cognitive control, is the most parsimonious explanation for the array of higher cognitive deficits that are observed in the disorder.

Deficits have also been reported on perceptual tasks in schizophrenia, including those measuring perceptual thresholds, perceptual context effects and sensory gating, such as mismatch negativity, p50 suppression, and prepulse inhibition. There should be little doubt that perception is altered in schizophrenia given the prominence of hallucinatory behavior in the symptomatology of the illness. However, the relationship between performance on perceptual tasks and higher cognitive deficits in schizophrenia is unknown, as indeed is the relationship between different perceptual tasks themselves. Some of the tasks involving perceptual discrimination would be conceptualized by cognitive neuroscientists as perceptual decision-making tasks (Heekeren et al, 2004; Wendelken et $a l, 2009$ ) and these have been shown to engage a distributed brain circuitry that includes the PFC, which is strongly engaged when subjects are pushed to their limit of perceptual discrimination. Others, such as mismatch paradigms, typically include a distractor task that involves reading or watching a movie. Functional imaging studies of these paradigms show that they also engage frontal networks (Molholm et al, 2005). Interestingly, in a study of perceptual organization, Silverstein et al (1996) showed a full recovery in performance to the normal range in patients simply by removing several conditions of the task to reduce strategyshifting demands, suggesting a role for altered cognitive control processes in these deficits. Other work showing intact subliminal priming in the context of lowered backward masking performance also suggests that low-level visual processes may be preserved, while top-down attentional and control mechanisms may be associated with impaired performance (Del Cul et al, 2006). Finally, psychophysical tasks involving staircasing methods for threshold discrimination are highly sensitive to attention lapses and, whereas some studies have controlled for this (Dakin et al, 2005), many such studies in schizophrenia have not. Hence, it is unclear as to what degree impaired performance on some tasks involving perceptual thresholds and discrimination might also reflect a generalized performance deficit.

Finally, it could be hypothesized that altered perceptual processing could result in higher cognitive deficits related to attention, executive functions, memory, and language processing in schizophrenia in a bottom-up manner. This is unlikely, however, because many studies have shown that stimuli such as words or images are processed quite normally in schizophrenia, fully to the semantic level, where they elicit normal or even increased priming effects. The opposite pattern, reduced priming, is seen when patients are required to rely on strategic processing (Barch et al, 1996b; Kerns and Berenbaum, 2002; Kreher et al, 2009). Using a degraded stimulus version of the AX CPT, Barch et al (1997) showed that, unlike the pattern typically seen in schizophrenia, healthy subjects working with degraded perceptual input show a general increase in error rates (generalized deficit pattern) and did not change the level of DLPFC activation during fMRI rather than the selective increase in $\mathrm{BX}$ errors and decrease in PFC activation that characterizes patients with schizophrenia. Understanding the relationship between deficits on the performance of tasks engaging higher cognitive functions such as attention, executive functions, memory and language process, which can readily be accounted for by the prefrontally mediated cognitive control model, and performance on measures of different aspects of perceptual processing would bring increased coherence to our understanding of the mechanisms of impaired brain function and behavior in schizophrenia, and should be an increased focus of future research.

\section{CONCLUSION}

A large body of evidence has accumulated implicating higher cognitive dysfunction as a core feature of schizophrenia that is associated with clinical features of the disorder (eg, disorganization, negative symptoms) and functional outcome. In addition, higher cognitive deficits are present in childhood, in various risk states (eg, genetic high risk, CHR), at the onset of the illness, and stably persist throughout the course of the disorder. Given the pervasive nature of these deficits, a great deal of effort has been put forth to characterize cognitive impairment and use these data to inform our understanding of the pathophysiology of schizophrenia as well as identify treatment targets. There has also been some progress using these methods to identify functional susceptibility genes.

In this review, we have described a model of impaired cognitive control that seeks to account for a notable proportion of higher cognitive deficits that have been discussed in the schizophrenia literature. Cognitive control regulates a wide array of cognitive systems (Carter et al, 1998; Posner and Abdullaev, 1996) and is not restricted to a particular cognitive domain (Banich, 1997; Smith and 
Jonides, 1999). For example, in addition to accounting for deficits in attention and working memory, the cognitive control model posits that episodic memory deficits may be driven primarily by frontally mediated encoding and retrieval failures rather than a hippocampally mediated inability to learn (Ragland et al, 2009). In addition, we outlined data that might indicate the pathophysiological basis of impaired cognitive control, starting at the 'microcircuit' cellular level where functional alterations of the chandelier subtype of GABA-ergic interneurons in the DLPFC may result in reduced neuronal synchrony followed by subsequent prefrontal cortical dysfunction (for a review see, Lewis et al, 2005) and associated BOLD response reductions. Dysfunctional prefrontal recruitment of task appropriate networks during cognitive control represents 'macro-circuit' systems-level abnormalities that in turn lead to the impaired cognitive performance and behavioral disorganization.

Although we are focusing on a model of prefrontally based cognitive deficits, it is important to note that we are in no way implying that only the PFC is impaired in schizophrenia. Abnormalities in post-mortem tissue as well as morphometric and functional imaging changes have been reported in a wide range of brain regions, including the hippocampus, thalamus, superior temporal gyrus, and visual cortex (Benes et al, 2001; Dorph-Petersen et al, 2007; Ellison-Wright et al, 2008; Glahn et al, 2008; Honea et al, 2005; Wright et al, 2000). By formulating this model based on the evidence presented above, we propose that altered PFC function is likely to be a central driver in impaired cognition in schizophrenia and that a detailed understanding of the nature of impaired function in this neural system can inform our understanding not only of cognitive deficits in schizophrenia but also key targets for intervention. Importantly, our model, which attempts to link impaired local circuit dysfunction in the DLPFC to impaired distributed network dysfunction and a broad range of cognitive and functional impairments, has implications far beyond the simple notion that the DLPFC is affected in schizophrenia. The developmental, cellular, and molecular processes underlying local circuit function in the DLPFC should and are receiving a great deal of attention in research that seeks to understand pathophysiology and treatment targets. Cognitive neuroscience tasks implemented in imaging and cognitive EEG are providing a new generation of phenotypic measures that can help clarify the boundaries and overlap between schizophrenia and other serious mental disorders as well as to understand the functional significance of schizophrenia-related genetic variation. Furthermore, an understanding of the role of cognitive control can inform the development of cognitive training technologies, which to date are the only viable treatment approaches to impaired cognition in schizophrenia.

To this end, cognition is an important emerging treatment target in schizophrenia. The role of neurotransmitter systems in modulating prefrontal cortical function has become increasingly well understood and these systems have been identified as important treatment targets. Accordingly, there is preliminary evidence that catecholamine and other agents improve PFC function and cognition, including in schizophrenia patients. Although there have been variable outcomes among recent clinical trials of novel agents that act on catecholamine, glutamate, and cholinergic systems, these studies are complex and must overcome methodological challenges. Nonetheless, monoamine and amino-acid transmitter systems remain promising targets.

\section{FUTURE RESEARCH DIRECTIONS}

Although we have accumulated a large body of knowledge with regard to the course of the disorder after onset and factors influencing outcome, one of the most rapidly expanding areas of research is investigating how to accurately identify those individuals who will go on to develop schizophrenia. This area of research is particularly important as these findings promote early intervention, which has the potential to alter the trajectory of the illness for those at highest risk and reduce the burden on individuals, their families, and the health-care system. As discussed previously, there is evidence of cognitive deficits before the onset of the illness; however, there is limited knowledge as to when cognitive dysfunction emerges and how these deficits progress throughout childhood and adolescence. In addition, it remains unclear whether deficits at the population level in pre-adolescent samples are uniform across the sample or whether they reflect a subgroup with developmental pathology. These types of questions require prospective, most likely multicenter, studies that examine at-risk individuals in youth and continue through years after the disorder may manifest. Although the majority of current studies of at-risk youth measure clinical factors associated with transition to psychosis, future studies would benefit from examining cognitive predictors of conversion as well.

Treatment research may benefit substantially from the use of measures and methods that are linked to the function of neural systems, including behavioral and imaging measures from cognitive neuroscience, which might not have traditionally been included in the treatment development process. Such methods offer unique advantages for translational research, as many cognitive processes and their associated neural systems are preserved across species. Substantial interest in optimizing research in this way has led to recent initiatives such as CNTRICS (Carter and Barch, 2007; Carter et al, 2008; www.cntrics.ucdavis.edu). However, it is challenging to optimize the measurement properties of these sorts of tools and substantial work remains to be carried out before valid reliable imaging biomarkers will be developed and optimized for the purpose of enhancing translational research.

Finally, ongoing research into pharmacotherapy for impaired cognition in schizophrenia will also need to address patient heterogeneity by developing tailored treatment based on phenotypic (eg, cognitive symptoms, 
disorganization) and possibly genotypic variability. Such a personalized approach may allow us to get greater traction on the elusive problem of developing a successful treatment for the cognitive deficits that form a functional 'glass ceiling' for many people with schizophrenia.

\section{DISCLOSURE}

Drs Lesh, Niendam, and Minzenberg have no disclosures to report. Dr Carter has served as a consultant for Pfizer, Lilly, Merck, and Servier, and receives research funding from Glaxo-Smith Kline.

\section{REFERENCES}

Abi-Dargham A, Mawlawi O, Lombardo I, Gil R, Martinez D, Huang Y et al (2002). Prefrontal dopamine D1 receptors and working memory in schizophrenia. J Neurosci 22: 3708-3719.

Addington J, Addington D (1999). Neurocognitive and social functioning in schizophrenia. Schizophr Bull 25: 173-182.

Addington J, Addington D (2000). Neurocognitive and social functioning in schizophrenia: a 2.5 year follow-up study. Schizophr Res 44: 47-56. This paper used a broad clinical neuropsychological battery and multiple tests of psychosocial functioning in a large sample of patients with schizophrenia, showing that various aspects of cognitive functioning were associated with social and role functioning

Addington J, McCleary L, Munroe-Blum H (1998). Relationship between cognitive and social dysfunction in schizophrenia. Schizophr Res 34: 59-66. This study showed that verbal memory and vigilance were predictive of long-term social functioning and social problem solving in schizophrenia patients over 2 years later.

Akil M, Pierri JN, Whitehead RE, Edgar CL, Mohila C, Sampson AR et al (1999). Lamina-specific alterations in the dopamine innervation of the prefrontal cortex in schizophrenic subjects. Am J Psychiatry 156: 1580-1589.

Aleman A, Hijman R, de Haan EH, Kahn RS (1999). Memory impairment in schizophrenia: a meta-analysis. Am J Psychiatry 156: 1358-1366.

Allen NC, Bagade S, McQueen MB, loannidis JP, Kavvoura FK, Khoury MJ et al (2008). Systematic meta-analyses and field synopsis of genetic association studies in schizophrenia: the SzGene database. Nat Genet 40: 827-834.

Anagnostaras SG, Murphy GG, Hamilton SE, Mitchell SL, Rahnama NP, Nathanson NM et al (2003). Selective cognitive dysfunction in acetylcholine M1 muscarinic receptor mutant mice. Nat Neurosci 6: 51-58.

Andreasen NC, Rezai K, Alliger R, Swayze II WW, Flaum M, Kirchner P et al (1992). Hypofrontality in neuroleptic-naive patients and in patients with chronic schizophrenia. Assessment with xenon 133 single-photon emission computed tomography and the Tower of London. Arch Gen Psychiatry 49: 943-958. This paper showed decreased activation of prefrontal and parietal regions in response to a common measure of executive functioning (Tower of London) in neuroleptic-naïve and chronic schizophrenia patients in contrast to healthy controls, and the level of hypofrontality was associated with severity of patients' negative symptoms.

Apud JA, Mattay V, Chen J, Kolachana BS, Callicott JH, Rasetti R et al (2007). Tolcapone improves cognition and cortical information processing in normal human subjects. Neuropsychopharmacology 32: 1011-1020.

Asaad WF, Rainer G, Miller EK (2000). Task-specific neural activity in the primate prefrontal cortex. J Neurophysiol 84: 451-459.

Banich M (1997). Neuropsychology: The Neural Bases of Mental Function. Houghton Mifflin: Boston, MA.

Barch DM, Berenbaum H (1996a). Language production and thought disorder in schizophrenia. J Abnorm Psychol 105: 81-88.

Barch DM, Braver TS, Nystrom LE, Forman SD, Noll DC, Cohen JD (1997). Dissociating working memory from task difficulty in human prefrontal cortex. Neuropsychologia 35: 1373-1380.

Barch DM, Carter CS (2005). Amphetamine improves cognitive function in medicated individuals with schizophrenia and in healthy volunteers. Schizophr Res 77: 43-58.

Barch DM, Carter CS, Braver TS, Sabb FW, MacDonald III A, Noll DC et al (2001). Selective deficits in prefrontal cortex function in medication-naive patients with schizophrenia. Arch Gen Psychiatry 58: 280-288. This paper showed selective reductions in DLPFC activity in response to context processing demands in neuroleptic-naïve schizophrenia patients when compared with controls, supporting the hypothesis that working memory deficits in schizophrenia indicate impaired cognitive control.

Barch DM, Cohen JD, Servan-Schreiber D, Steingard S, Cohen JD, Steinhauer SS et al (1996b). Semantic priming in schizophrenia: an examination of spreading activation using word pronunciation and multiple SOAs. J Abnorm Psychol 105: 592-601

Barnett JH, Jones PB, Robbins TW, Muller U (2007). Effects of the catechol-Omethyltransferase Val158Met polymorphism on executive function: a metaanalysis of the Wisconsin Card Sort Test in schizophrenia and healthy controls. Mol Psychiatry 12: 502-509.

Bartok E, Berecz R, Glaub T, Degrell I (2005). Cognitive functions in prepsychotic patients. Prog Neuropsychopharmacol Biol Psychiatry 29: 621-625.

Becker TM, Kerns JG, Macdonald III AW, Carter CS (2008). Prefrontal dysfunction in first-degree relatives of schizophrenia patients during a stroop task. Neuropsychopharmacology 33: 2619-2625.

Bell MD, Bryson G (2001). Work rehabilitation in schizophrenia: does cognitive impairment limit improvement? Schizophr Bull 27: 269-279.

Benes FM, Vincent SL, Todtenkopf M (2001). The density of pyramidal and nonpyramidal neurons in anterior cingulate cortex of schizophrenic and bipolar subjects. Biol Psychiatry 50: 395-406.

Bertisch H, Li D, Hoptman MJ, Delisi LE (2010). Heritability estimates for cognitive factors and brain white matter integrity as markers of schizophrenia. Am J Med Genet B 153B: 885-894.

Bilder RM, Goldman RS, Robinson D, Reiter G, Bell L, Bates JA et al (2000). Neuropsychology of first-episode schizophrenia: initial characterization and clinical correlates. Am J Psychiatry 157: 549-559.

Bilder RM, Volavka J, Czobor P, Malhotra AK, Kennedy JL, Ni X et al (2002). Neurocognitive correlates of the COMT Val(158)Met polymorphism in chronic schizophrenia. Biol Psychiatry 52: 701-707.

Borgwardt SJ, McGuire P, Fusar-Poli P, Radue EW, Riecher-Rossler A (2008). Anterior cingulate pathology in the prodromal stage of schizophrenia. Neuroimage 39: 553-554.

Borgwardt SJ, McGuire PK, Aston J, Berger G, Dazzan P, Gschwandtner U et al (2007a). Structural brain abnormalities in individuals with an at-risk mental state who later develop psychosis. Br J Psychiatry Supp/ 51: s69-s75.

Borgwardt SJ, Riecher-Rossler A, Dazzan P, Chitnis X, Aston J, Drewe M et al (2007b). Regional gray matter volume abnormalities in the at risk mental state. Biol Psychiatry 61: 1148-1156.

Botvinick MM, Braver TS, Barch DM, Carter CS, Cohen JD (2001). Conflict monitoring and cognitive control. Psychol Rev 108: 624-652.

Bowen L, Wallace CJ, Glynn SM, Nuechterlein KH, Lutzker JR, Kuehnel TG (1994). Schizophrenic individuals' cognitive functioning and performance in interpersonal interactions and skills training procedures. J Psychiatr Res 28: 289-301.

Braff DL, Light GA (2005). The use of neurophysiological endophenotypes to understand the genetic basis of schizophrenia. Dialogues Clin Neurosci 7: 125-135.

Brass M, von Cramon DY (2002). The role of the frontal cortex in task preparation. Cereb Cortex 12: 908-914.

Braver TS, Cohen JD, Barch DM (2002). The Role of Prefrontal Cortex in Normal and Disordered Cognitive Control: A Cognitive Neuroscience Perspective. Oxford University Press: New York, NY.

Braver TS, Reynolds JR, Donaldson DI (2003). Neural mechanisms of transient and sustained cognitive control during task switching. Neuron 39: 713-726.

Breier A, Schreiber JL, Dyer J, Pickar D (1991). National Institute of Mental Health longitudinal study of chronic schizophrenia. Prognosis and predictors of outcome. Arch Gen Psychiatry 48: 239-246. This paper on the long-term outcome of $\mathbf{5 8}$ individuals with chronic schizophrenia show that neuropsychological measures of prefrontal functioning were significantly correlated with long-term outcome of negative symptoms and social functioning but not positive symptoms

Brekke JS, Raine A, Ansel M, Lencz T, Bird L (1997). Neuropsychological and psychophysiological correlates of psychosocial functioning in schizophrenia. Schizophr Bull 23: 19-28.

Brewer W, Francey S, Wood S, Jackson H, Pantelis C, Phillips L et al (2005). Memory impairments identified in people at ultra-high risk for psychosis who later develop first-episode psychosis. Am J Psychiatry 162: 71-78.

Brewer W, Wood S, McGorry P, Francey S, Phillips L, Yung A et al (2003). Impairment of olfactory identification ability in individuals at ultra-high risk for psychosis who later develop schizophrenia. Am J Psychiatry 160: 1790-1794.

Broome MR, Matthiasson P, Fusar-Poli P, Woolley JB, Johns LC, Tabraham P et al (2009). Neural correlates of executive function and working memory in the 'at-risk mental state'. Br J Psychiatry 194: 25-33.

Brown AS, Derkits EJ (2010). Prenatal infection and schizophrenia: a review of epidemiologic and translational studies. Am J Psychiatry 167: 261-280. 
Brozoski TJ, Brown RM, Rosvold HE, Goldman PS (1979). Cognitive deficit caused by regional depletion of dopamine in prefrontal cortex of rhesus monkey. Science 205: 929-932. This classical paper established the crucial role of dopamine in the prefrontal cortex during a spatial delayed alternation task.

Buchanan RW, Davis M, Goff D, Green MF, Keefe RS, Leon AC et al (2005). A summary of the FDA-NIMH-MATRICS workshop on clinical trial design for neurocognitive drugs for schizophrenia. Schizophr Bull 31: 5-19.

Buchanan RW, Javitt DC, Marder SR, Schooler NR, Gold JM, McMahon RP et al (2007). The Cognitive and Negative Symptoms in Schizophrenia Trial (CONSIST): the efficacy of glutamatergic agents for negative symptoms and cognitive impairments. Am J Psychiatry 164: 1593-1602.

Buchsbaum MS, Someya T, Teng CY, Abel L, Chin S, Najafi A et al (1996). PET and MRI of the thalamus in never-medicated patients with schizophrenia. Am J Psychiatry 153: 191-199.

Bunge SA, Hazeltine E, Scanlon MD, Rosen AC, Gabrieli JD (2002). Dissociable contributions of prefrontal and parietal cortices to response selection. Neuroimage 17: 1562-1571.

Bunge SA, Kahn I, Wallis JD, Miller EK, Wagner AD (2003). Neural circuits subserving the retrieval and maintenance of abstract rules. J Neurophysiol $\mathbf{9 0}$ 3419-3428.

Burdick KE, Goldberg TE, Funke B, Bates JA, Lencz T, Kucherlapati R et al (2007). DTNBP1 genotype influences cognitive decline in schizophrenia. Schizophr Res 89: 169-172.

Calkins ME, Curtis CE, lacono WG, Grove WM (2004). Antisaccade performance is impaired in medically and psychiatrically healthy biological relatives of schizophrenia patients. Schizophr Res 71: 167-178.

Cannon TD, Bearden CE, Hollister JM, Rosso IM, Sanchez LE, Hadley T (2000a). Childhood cognitive functioning in schizophrenia patients and their unaffected siblings: a prospective cohort study. Schizophr Bull 26: 379-393.

Cannon TD, Huttunen MO, Lonnqvist J, Tuulio-Henriksson A, Pirkola T, Glahn D et al (2000b). The inheritance of neuropsychological dysfunction in twins discordant for schizophrenia. Am J Hum Genet 67: 369-382.

Cannon TD, Kaprio J, Lonnqvist J, Huttunen M, Koskenvuo M (1998). The genetic epidemiology of schizophrenia in a Finnish twin cohort. A population-based modeling study. Arch Gen Psychiatry 55: 67-74.

Cannon TD, Keller MC (2006). Endophenotypes in the genetic analyses of mental disorders. Annu Rev Clin Psychol 2: 267-290.

Cannon TD, Rosso IM, Hollister JM, Bearden CE, Sanchez LE, Hadley T (2000c). A prospective cohort study of genetic and perinatal influences in the etiology of schizophrenia. Schizophr Bull 26: 351-366.

Cannon TD, Thompson PM, van Erp TG, Toga AW, Poutanen VP, Huttunen M et al (2002). Cortex mapping reveals regionally specific patterns of genetic and disease-specific gray-matter deficits in twins discordant for schizophrenia. Proc Natl Acad Sci USA 99: 3228-3233. This twin study showed elucidated genetic- and disease-specific gray matter deficits in the prefrontal cortex.

Cardno AG, Marshall EJ, Coid B, Macdonald AM, Ribchester TR, Davies NJ et al (1999). Heritability estimates for psychotic disorders: the Maudsley twin psychosis series. Arch Gen Psychiatry 56: 162-168.

Carlsson A, Carlsson ML (2006). A dopaminergic deficit hypothesis of schizophrenia: the path to discovery. Dialogues Clin Neurosci 8: 137-142.

Carpenter WT, Gold JM (2002). Another view of therapy for cognition in schizophrenia. Biol Psychiatry 51: 969-971.

Carter CS (2005). Applying new approaches from cognitive neuroscience to enhance drug development for the treatment of impaired cognition in schizophrenia. Schizophr Bull 31: 810-815. This paper describes the potential value of utilizing tasks from cognitive neuroscience that isolate particular cognitive processes that are more specifically tied to neural systems in the treatment development process.

Carter CS, Barch DM (2007). Cognitive neuroscience-based approaches to measuring and improving treatment effects on cognition in schizophrenia: the CNTRICS initiative. Schizophr Bull 33: 1131-1137.

Carter CS, Barch DM, Buchanan RW, Bullmore E, Krystal JH, Cohen J et al (2008). Identifying cognitive mechanisms targeted for treatment development in schizophrenia: an overview of the first meeting of the Cognitive Neuroscience Treatment Research to Improve Cognition in Schizophrenia Initiative. Biol Psychiatry 64: 4-10.

Carter CS, Botvinick MM, Cohen JD (1999). The contribution of the anterior cingulate cortex to executive processes in cognition. Rev Neurosci 10: 49-57.

Carter CS, Braver TS, Barch DM, Botvinick MM, Noll D, Cohen JD (1998). Anterior cingulate cortex, error detection, and the online monitoring of performance. Science 280: 747-749.

Carter CS, Robertson LC, Nordahl TE (1992). Abnormal processing of irrelevant information in chronic schizophrenia: selective enhancement of Stroop facilitation. Psychiatry Res 41: 137-146.
Carter CS, Robertson LC, Nordahl TE, Chaderjian M, Oshora-Celaya L (1996). Perceptual and attentional asymmetries in schizophrenia: further evidence for a left hemisphere deficit. Psychiatry Res 62: 111-119.

Castner SA, Williams GV, Goldman-Rakic PS (2000). Reversal of antipsychoticinduced working memory deficits by short-term dopamine D1 receptor stimulation. Science 287: 2020-2022. This study revealed detailed mechanisms related to the role of dopamine D1 receptors in mediating DA effects on working memory-related neuronal activity in the prefrontal cortex.

Censits DM, Ragland JD, Gur RC, Gur RE (1997). Neuropsychological evidence supporting a neurodevelopmental model of schizophrenia: a longitudinal study. Schizophr Res 24: 289-298.

Cho RY, Ford JM, Krystal JH, Laruelle M, Cuthbert B, Carter CS (2005). Functional neuroimaging and electrophysiology biomarkers for clinical trials for cognition in schizophrenia. Schizophr Bull 31: 865-869.

Cho RY, Konecky RO, Carter CS (2006). Impairments in frontal cortical gamma synchrony and cognitive control in schizophrenia. Proc Natl Acad Sci USA 103: 19878-19883. This investigation was the first to reveal that schizophrenia patients show reduced induced gamma band activity over the PFC during cognitive control in schizophrenia. Reduced gamma power was associated with poor task performance and disorganization in patients.

Choi JS, Kang DH, Park JY, Jung WH, Choi CH, Chon MW et al (2008). Cavum septum pellucidum in subjects at ultra-high risk for psychosis: compared with first-degree relatives of patients with schizophrenia and healthy volunteers. Prog Neuropsychopharmacol Biol Psychiatry 32: 1326-1330.

Clare L, McKenna PJ, Mortimer AM, Baddeley AD (1993). Memory in schizophrenia: what is impaired and what is preserved? Neuropsychologia 31: 1225-1241.

Cohen JD, Barch DM, Carter C, Servan-Schreiber D (1999). Context-processing deficits in schizophrenia: converging evidence from three theoretically motivated cognitive tasks. J Abnorm Psychol 108: 120-133. This study showed cognitive control deficits across three separate tasks in patients with schizophrenia that were distinct from both depressed and healthy control groups.

Cohen JD, Botvinick M, Carter CS (2000). Anterior cingulate and prefrontal cortex: who's in control? Nat Neurosci 3: 421-423.

Cohen JD, Dunbar K, McClelland JL (1990). On the control of automatic processes: a parallel distributed processing account of the Stroop effect. Psychol Rev 97: 332-361.

Condray R, van Kammen DP, Steinhauer SR, Kasparek A, Yao JK (1995). Language comprehension in schizophrenia: trait or state indicator? Biol Psychiatry 38: 287-296.

Cornblatt B, Obuchowski M, Roberts S, Pollack S, Erlenmeyer-Kimling L (1999). Cognitive and behavioral precursors of schizophrenia. Dev Psychopathol 11: 487-508.

Cornblatt BA (2002). The New York high risk project to the Hillside recognition and prevention (RAP) program. Am J Med Genet 114: 956-966.

Cornblatt BA, Lenzenweger MF, Erlenmeyer-Kimling L (1989). The continuous performance test, identical pairs version: II. Contrasting attentional profiles in schizophrenic and depressed patients. Psychiatry Res 29: 65-85.

Corrigan PW, Toomey R (1995). Interpersonal problem solving and information processing in schizophrenia. Schizophr Bull 21: 395-403.

Cosway R, Byrne M, Clafferty R, Hodges A, Grant E, Abukmeil SS et al (2000). Neuropsychological change in young people at high risk for schizophrenia: results from the first two neuropsychological assessments of the Edinburgh High Risk Study. Psychol Med 30: 1111-1121.

Coyle JT (2006). Glutamate and schizophrenia: beyond the dopamine hypothesis. Cell Mol Neurobiol 26: 365-384.

Crook JM, Tomaskovic-Crook E, Copolov DL, Dean B (2000). Decreased muscarinic receptor binding in subjects with schizophrenia: a study of the human hippocampal formation. Biol Psychiatry 48: 381-388.

Crook JM, Tomaskovic-Crook E, Copolov DL, Dean B (2001). Low muscarinic receptor binding in prefrontal cortex from subjects with schizophrenia: a study of Brodmann's areas 8, 9, 10, and 46 and the effects of neuroleptic drug treatment. Am J Psychiatry 158: 918-925.

D'Esposito M, Postle BR (2002). The Neural Basis of Working Memory Storage, Rehearsal, and Control Processes: Evidence from Patient and Functional Magnetic Resonance Imaging Studies. Guilford Press: New York, NY.

D'Souza DC, Perry E, MacDougall L, Ammerman Y, Cooper T, Wu YT et al (2004). The psychotomimetic effects of intravenous delta-9-tetrahydrocannabinol in healthy individuals: implications for psychosis. Neuropsychopharmacology 29: 1558-1572.

Dakin S, Carlin P, Hemsley D (2005). Weak suppression of visual context in chronic schizophrenia. Curr Biol 15: R822-R824.

Daniel DG, Weinberger DR, Jones DW, Zigun JR, Coppola R, Handel S et al (1991). The effect of amphetamine on regional cerebral blood flow during cognitive activation in schizophrenia. J Neurosci 11: 1907-1917. 
Daw ND, Kakade S, Dayan P (2002). Opponent interactions between serotonin and dopamine. Neural Network 15: 603-616.

Dean B, Sundram S, Bradbury R, Scarr E, Copolov D (2001). Studies on [ $\left.{ }^{3} \mathrm{H}\right] \mathrm{CP}-$ 55940 binding in the human central nervous system: regional specific changes in density of cannabinoid-1 receptors associated with schizophrenia and cannabis use. Neuroscience 103: 9-15.

Del Cul A, Dehaene S, Leboyer M (2006). Preserved subliminal processing and impaired conscious access in schizophrenia. Arch Gen Psychiatry 63: 1313-1323.

Delawalla Z, Csernansky JG, Barch DM (2008). Prefrontal cortex function in nonpsychotic siblings of individuals with schizophrenia. Biol Psychiatry 63: 490-497.

Dibben CR, Rice C, Laws K, McKenna PJ (2009). Is executive impairment associated with schizophrenic syndromes? A meta-analysis. Psychol Med 39: 381-392.

Dickerson F, Boronow JJ, Ringel N, Parente F (1996). Neurocognitive deficits and social functioning in outpatients with schizophrenia. Schizophr Res 21: 75-83.

Dickinson D, Ramsey ME, Gold JM (2007). Overlooking the obvious: a metaanalytic comparison of digit symbol coding tasks and other cognitive measures in schizophrenia. Arch Gen Psychiatry 64: 532-542.

Diwadkar VA, Montrose DM, Dworakowski D, Sweeney JA, Keshavan MS (2006). Genetically predisposed offspring with schizotypal features: an ultra high-risk group for schizophrenia? Prog Neuropsychopharmacol Biol Psychiatry 30: 230-238.

Docherty NM, DeRosa M, Andreasen NC (1996). Communication disturbances in schizophrenia and mania. Arch Gen Psychiatry 53: 358-364.

Docherty N, Schnur M, Harvey PD (1988). Reference performance and positive and negative thought disorder: a follow-up study of manics and schizophrenics. J Abnorm Psychol 97: 437-442.

Donohoe G, Frodl T, Morris D, Spoletini I, Cannon DM, Cherubini A et al (2010). Reduced occipital and prefrontal brain volumes in dysbindin-associated schizophrenia. Neuropsychopharmacology 35: 368-373.

Donohoe G, Morris DW, Clarke S, McGhee KA, Schwaiger S, Nangle JM et al (2007). Variance in neurocognitive performance is associated with dysbindin-1 in schizophrenia: a preliminary study. Neuropsychologia 45: 454-458.

Dorph-Petersen KA, Pierri JN, Wu Q, Sampson AR, Lewis DA (2007). Primary visual cortex volume and total neuron number are reduced in schizophrenia. J Comp Neurol 501: 290-301.

Dove A, Pollmann S, Schubert T, Wiggins CJ, von Cramon DY (2000). Prefrontal cortex activation in task switching: an event-related fMRI study. Brain Res Cogn Brain Res 9: 103-109.

Dreher JC, Koechlin E, Ali SO, Grafman J (2002). The roles of timing and task order during task switching. Neuroimage 17: 95-109.

Eastvold AD, Heaton RK, Cadenhead KS (2007). Neurocognitive deficits in the (putative) prodrome and first episode of psychosis. Schizophr Res 93: 266-277.

Egan MF, Goldberg TE, Gscheidle T, Weirich M, Rawlings R, Hyde TM et al (2001a). Relative risk for cognitive impairments in siblings of patients with schizophrenia. Biol Psychiatry 50: 98-107.

Egan MF, Goldberg TE, Kolachana BS, Callicott JH, Mazzanti CM, Straub RE et al (2001b). Effect of COMT Val108/158 Met genotype on frontal lobe function and risk for schizophrenia. Proc Natl Acad Sci USA 98: 6917-6922. This study was one of the first to show the effect of COMT allelic load on prefrontal function during executive tasks.

Egerton A, Allison C, Brett RR, Pratt JA (2006). Cannabinoids and prefrontal cortical function: insights from preclinical studies. Neurosci Biobehav Rev 30: 680-695.

Egner T, Hirsch J (2005). Cognitive control mechanisms resolve conflict through cortical amplification of task-relevant information. Nat Neurosci 8: 1784-1790.

Eisenberg DP, Berman KF (2010). Executive function, neural circuitry, and genetic mechanisms in schizophrenia. Neuropsychopharmacology 35: 258-277.

Ellison-Wright I, Glahn DC, Laird AR, Thelen SM, Bullmore E (2008). The anatomy of first-episode and chronic schizophrenia: an anatomical likelihood estimation meta-analysis. Am J Psychiatry 165: 1015-1023.

Erlenmeyer-Kimling L, Rock D, Roberts SA, Janal M, Kestenbaum C, Cornblatt B et al (2000). Attention, memory, and motor skills as childhood predictors of schizophrenia-related psychoses: the New York High-Risk Project. Am J Psychiatry 157: 1416-1422.

Esbenshade TA, Fox GB, Cowart MD (2006). Histamine H3 receptor antagonists: preclinical promise for treating obesity and cognitive disorders. Mol Interv 6: 77-88, 59.

Fan JB, Zhang CS, Gu NF, Li XW, Sun WW, Wang HY et al (2005). Catechol-Omethyltransferase gene $\mathrm{Val} /$ Met functional polymorphism and risk of schizophrenia: a large-scale association study plus meta-analysis. Biol Psychiatry 57: 139-144.

Faraone SV, Seidman LJ, Kremen WS, Pepple JR, Lyons MJ, Tsuang MT (1995). Neuropsychological functioning among the nonpsychotic relatives of schizo- phrenic patients: a diagnostic efficiency analysis. I Abnorm Psychol 104: 286-304.

Faraone SV, Seidman LJ, Kremen WS, Toomey R, Pepple JR, Tsuang MT (1999). Neuropsychological functioning among the nonpsychotic relatives of schizophrenic patients: a 4-year follow-up study. J Abnorm Psychol 108: 176-181.

Feinberg I (1982). Schizophrenia: caused by a fault in programmed synaptic elimination during adolescence? J Psychiatr Res 17: 319-334. This important conceptual paper introduced the highly influential 'pruning' hypothesis of schizophrenia, which suggests that abnormal rates of programmed cell elimination occurring during adolescence contributes to the development of cognitive impairment and psychotic symptoms associated with schizophrenia.

Ferreri F, Agbokou C, Gauthier S (2006). Cognitive dysfunctions in schizophrenia: potential benefits of cholinesterase inhibitor adjunctive therapy. J Psychiatry Neurosci 31: 369-376.

Filbey FM, Toulopoulou T, Morris RG, McDonald C, Bramon E, Walshe M et al (2008). Selective attention deficits reflect increased genetic vulnerability to schizophrenia. Schizophr Res 101: 169-175.

Finkelstein JR, Cannon TD, Gur RE, Gur RC, Moberg P (1997). Attentional dysfunctions in neuroleptic-naive and neuroleptic-withdrawn schizophrenic patients and their siblings. J Abnorm Psychol 106: 203-212.

Fornito A, Yung AR, Wood SJ, Phillips LJ, Nelson B, Cotton S et al (2008). Anatomic abnormalities of the anterior cingulate cortex before psychosis onset: an MRI study of ultra-high-risk individuals. Biol Psychiatry 64: 758-765.

Francey SM, Jackson HJ, Phillips LJ, Wood SJ, Yung AR, McGorry PD (2005). Sustained attention in young people at high risk of psychosis does not predict transition to psychosis. Schizophr Res 79: 127-136.

Franke P, Maier W, Hardt J, Hain C (1993). Cognitive functioning and anhedonia in subjects at risk for schizophrenia. Schizophr Res 10: 77-84.

Franowicz JS, Arnsten AF (1998). The alpha-2a noradrenergic agonist, guanfacine, improves delayed response performance in young adult rhesus monkeys. Psychopharmacology (Berl) 136: 8-14.

Freedman R, Olincy A, Buchanan RW, Harris JG, Gold JM, Johnson L et al (2008). Initial phase 2 trial of a nicotinic agonist in schizophrenia. Am J Psychiatry 165 1040-1047.

Freedman R, Olincy A, Ross RG, Waldo MC, Stevens KE, Adler LE et al (2003). The genetics of sensory gating deficits in schizophrenia. Curr Psychiatry Rep 5: 155-161.

Friedman Jl, Carpenter D, Lu J, Fan J, Tang CY, White L et al (2008). A pilot study of adjunctive atomoxetine treatment to second-generation antipsychotics for cognitive impairment in schizophrenia. J Clin Psychopharmacol 28: 59-63.

Funahashi S, Inoue M, Kubota K (1993). Delay-related activity in the primate prefrontal cortex during sequential reaching tasks with delay. Neurosci Res 18: $171-175$

Fusar-Poli P, Howes OD, Allen P, Broome M, Valli I, Asselin MC et al (2010). Abnormal frontostriatal interactions in people with prodromal signs of psychosis: a multimodal imaging study. Arch Gen Psychiatry 67: 683-691.

Fuster JM (1990). Behavioral electrophysiology of the prefrontal cortex of the primate. Prog Brain Res 85: 313-323; discussion 323-314.

Fuster JM (2002). Frontal lobe and cognitive development. J Neurocytol 31: 373-385.

Galambos R (ed). (1992). A Comparison of Certain Gamma Band (40-Hz) Brain Rhythms in Cat and Man. Birkhauser: Boston, MA.

Giuffrida A, Leweke FM, Gerth CW, Schreiber D, Koethe D, Faulhaber J et al (2004). Cerebrospinal anandamide levels are elevated in acute schizophrenia and are inversely correlated with psychotic symptoms. Neuropsychopharmacology 29: 2108-2114.

Glahn DC, Cannon TD, Gur RE, Ragland JD, Gur RC (2000). Working memory constrains abstraction in schizophrenia. Biol Psychiatry 47: 34-42.

Glahn DC, Laird AR, Ellison-Wright I, Thelen SM, Robinson JL, Lancaster JL et al (2008). Meta-analysis of gray matter anomalies in schizophrenia: application of anatomic likelihood estimation and network analysis. Biol Psychiatry 64: 774-781. An up-to-date structural meta-analysis that identified reduced gray matter density in schizophrenia patients compared with controls, including the middle frontal gyrus and anterior cingulate.

Glahn DC, Ragland JD, Abramoff A, Barrett J, Laird AR, Bearden CE et al (2005). Beyond hypofrontality: a quantitative meta-analysis of functional neuroimaging studies of working memory in schizophrenia. Hum Brain Mapp 25: 60-69.

Glahn DC, Therman S, Manninen M, Huttunen M, Kaprio J, Lonnqvist J et al (2003). Spatial working memory as an endophenotype for schizophrenia. Biol Psychiatry 53: 624-626.

Glantz LA, Lewis DA (2000). Decreased dendritic spine density on prefrontal cortical pyramidal neurons in schizophrenia. Arch Gen Psychiatry 57: 65-73. This critical study showed a decrease in dendritic spine density in the DLPFC in 
patients with schizophrenia and contributed to our understanding of the cellular basis for prefrontal dysfunction in the disorder.

Goff DC, Lamberti JS, Leon AC, Green MF, Miller AL, Patel J et al (2008). A placebo-controlled add-on trial of the Ampakine, CX516, for cognitive deficits in schizophrenia. Neuropsychopharmacology 33: 465-472.

Goghari VM, Rehm K, Carter CS, MacDonald III AW (2007). Regionally specific cortical thinning and gray matter abnormalities in the healthy relatives of schizophrenia patients. Cereb Cortex 17: 415-424.

Gold JM, Carpenter C, Randolph C, Goldberg TE, Weinberger DR (1997). Auditory working memory and Wisconsin Card Sorting Test performance in schizophrenia. Arch Gen Psychiatry 54: 159-165. This paper provides evidence that impairments on the Wisconsin Card Sorting task, which are commonly reported in schizophrenia, may be accounted for by impairments in working memory.

Goldberg TE, Goldman RS, Burdick KE, Malhotra AK, Lencz T, Patel RC et al (2007). Cognitive improvement after treatment with second-generation antipsychotic medications in first-episode schizophrenia: is it a practice effect? Arch Gen Psychiatry 64: 1115-1122.

Goldman-Rakic PS (1987). Development of cortical circuitry and cognitive function. Child Dev 58: 601-622.

Goldman-Rakic PS (1995). Architecture of the prefrontal cortex and the central executive. Ann N Y Acad Sci 769: 71-83. This seminal review offers an excellent synthesis of the neurobiological and cognitive science literature in outlining the role of the prefrontal cortex in executive functions.

Goldman RS, Axelrod BN, Tandon R, Ribeiro SC, Craig K, Berent S (1993). Neuropsychological prediction of treatment efficacy and one-year outcome in schizophrenia. Psychopathology 26: 122-126.

Gonzalez-Burgos G, Lewis DA (2008). GABA neurons and the mechanisms of network oscillations: implications for understanding cortical dysfunction in schizophrenia. Schizophr Bull 34: 944-961. This comprehensive review presented evidence that mediation by gamma-aminobutyric acid neurons is crucial for synchronized network oscillations, which may underlie impaired higher cognition in schizophrenia.

Gottesman II, Gould TD (2003). The endophenotype concept in psychiatry: etymology and strategic intentions. Am J Psychiatry 160: 636-645.

Gray JA, Roth BL (2007). Molecular targets for treating cognitive dysfunction in schizophrenia. Schizophr Bull 33: 1100-1119.

Green MF (1996). What are the functional consequences of neurocognitive deficits in schizophrenia? Am J Psychiatry 153: 321-330. This influential review paper first pointed out to the field that cognitive impairments were very strongly predictive of functional outcome in schizophrenia.

Green MF (1998). Schizophrenia from a Neurocognitive Perspective: Probing the Impenetrable Darkness. Allyn and Bacon: Boston, MA.

Green MF, Kern RS, Braff DL, Mintz J (2000). Neurocognitive deficits and functional outcome in schizophrenia: are we measuring the 'right stuff'? Schizophr Bull 26: 119-136.

Greenwood KE, Morris R, Sigmundsson T, Landau S, Wykes T (2008). Executive functioning in schizophrenia and the relationship with symptom profile and chronicity. J Int Neuropsychol Soc 14: 782-792.

Gschwandtner U, Aston J, Borgwardt S, Drewe M, Feinendegen C, Lacher D et al (2003). Neuropsychological and neurophysiological findings in individuals suspected to be at risk for schizophrenia: preliminary results from the Basel early detection of psychosis study-Fruherkennung von Psychosen (FEPSY). Acta Psychiatr Scand 108: 152-155.

Gschwandtner U, Pfluger M, Aston J, Borgwardt S, Drewe M, Stieglitz RD et al (2006). Fine motor function and neuropsychological deficits in individuals at risk for schizophrenia. Eur Arch Psychiatry Clin Neurosci 256: 201-206.

Gur RC, Gur RE (1995). Hypofrontality in schizophrenia: RIP. Lancet 345: 1383-1384.

Habets P, Krabbendam L, Hofman P, Suckling J, Oderwald F, Bullmore E et al (2008). Cognitive performance and grey matter density in psychosis: functional relevance of a structural endophenotype. Neuropsychobiology 58: 128-137.

Hambrecht M, Lammertink M, Klosterkotter J, Matuschek E, Pukrop R (2002). Subjective and objective neuropsychological abnormalities in a psychosis prodrome clinic. Br J Psychiatry Suppl 43: s30-s37.

Hamdani N, Tabeze JP, Ramoz N, Ades J, Hamon M, Sarfati Y et al (2008). The CNR1 gene as a pharmacogenetic factor for antipsychotics rather than a susceptibility gene for schizophrenia. Eur Neuropsychopharmacol 18: 34-40.

Harris JG, Adler LE, Young DA, Cullum CM, Rilling LM, Cicerello A et al (1996). Neuropsychological dysfunction in parents of schizophrenics. Schizophr Res 20: 253-260.

Harris JM, Moorhead TW, Miller P, Mclntosh AM, Bonnici HM, Owens DG et al (2007). Increased prefrontal gyrification in a large high-risk cohort characterizes those who develop schizophrenia and reflects abnormal prefrontal development. Biol Psychiatry 62: 722-729.
Harris JM, Whalley H, Yates S, Miller P, Johnstone EC, Lawrie SM (2004a). Abnormal cortical folding in high-risk individuals: a predictor of the development of schizophrenia? Biol Psychiatry 56: 182-189.

Harris JM, Yates S, Miller P, Best JJ, Johnstone EC, Lawrie SM (2004b). Gyrification in first-episode schizophrenia: a morphometric study. Biol Psychiatry 55: 141-147.

Harvey PD (1983). Speech competence in manic and schizophrenic psychoses: the association between clinically rated thought disorder and cohesion and reference performance. J Abnorm Psychol 92: 368-377.

Harvey PD, Keefe RS (2001). Studies of cognitive change in patients with schizophrenia following novel antipsychotic treatment. Am J Psychiatry 158: 176-184.

Hasenkamp W, Epstein MP, Green A, Wilcox L, Boshoven W, Lewison B et al (2010). Heritability of acoustic startle magnitude, prepulse inhibition, and startle latency in schizophrenia and control families. Psychiatry Res 178: 236-243.

Hawkins KA, Addington J, Keefe RS, Christensen B, Perkins DO, Zipurksy R et al (2004). Neuropsychological status of subjects at high risk for a first episode of psychosis. Schizophr Res 67: 115-122.

Heckers S (2001). Neuroimaging studies of the hippocampus in schizophrenia. Hippocampus 11: 520-528.

Heekeren HR, Marrett S, Bandettini PA, Ungerleider LG (2004). A general mechanism for perceptual decision-making in the human brain. Nature 431: 859-862. This functional neuroimaging study of a categorization task provided evidence that perceptual decisions are made by integrating evidence from sensory processing areas and that this integration may take place in the dorsolateral prefrontal cortex.

Heifets BD, Castillo PE (2009). Endocannabinoid signaling and long-term synaptic plasticity. Annu Rev Physiol 71: 283-306.

Henquet C, Di Forti M, Morrison P, Kuepper R, Murray RM (2008). Gene-environment interplay between cannabis and psychosis. Schizophr Bull 34: 1111-1121.

Heslegrave RJ, Awad AG, Voruganti LN (1997). The influence of neurocognitive deficits and symptoms on quality of life in schizophrenia. J Psychiatry Neurosci 22: 235-243.

Ho BC, Wassink TH, O'Leary DS, Sheffield VC, Andreasen NC (2005). Catechol-Omethyl transferase Val158Met gene polymorphism in schizophrenia: working memory, frontal lobe MRI morphology and frontal cerebral blood flow. $\mathrm{Mol}$ Psychiatry 10: 229, 287-298.

Hoff AL, Riordan H, O'Donnell DW, Morris L, DeLisi LE (1992). Neuropsychological functioning of first-episode schizophreniform patients. Am J Psychiatry 149: 898-903.

Holroyd CB, Coles MG (2002). The neural basis of human error processing: reinforcement learning, dopamine, and the error-related negativity. Psychol Rev 109: 679-709.

Honea R, Crow TJ, Passingham D, Mackay CE (2005). Regional deficits in brain volume in schizophrenia: a meta-analysis of voxel-based morphometry studies. Am J Psychiatry 162: 2233-2245.

Horacek J, Zavesicka L, Tintera J, Dockery C, Platilova V, Kopecek M et al (2005). The effect of tryptophan depletion on brain activation measured by functional magnetic resonance imaging during the Stroop test in healthy subjects. Physiol Res 54: 235-244.

Howard MW, Rizzuto DS, Caplan JB, Madsen JR, Lisman J, AschenbrennerScheibe R et al (2003). Gamma oscillations correlate with working memory load in humans. Cereb Cortex 13: 1369-1374.

Hurlemann R, Matusch A, Kuhn KU, Berning J, Elmenhorst D, Winz O et al (2008). 5 -HT2A receptor density is decreased in the at-risk mental state. Psychopharmacology (Berl) 195: 579-590.

Ingvar DH, Franzen G (1974). Abnormalities of cerebral blood flow distribution in patients with chronic schizophrenia. Acta Psychiatr Scand 50: 425-462.

Jacobsen CF (1936). Studies of cerebral function in primates: I. The functions of the frontal association areas in monkeys. Comp Psychol Monographs 13: 1-60.

Jakala P, Riekkinen M, Sirvio J, Koivisto E, Kejonen K, Vanhanen M et al (1999). Guanfacine, but not clonidine, improves planning and working memory performance in humans. Neuropsychopharmacology 20: 460-470.

Jay TM (2003). Dopamine: a potential substrate for synaptic plasticity and memory mechanisms. Prog Neurobiol 69: 375-390.

Jentsch JD, Trantham-Davidson H, Jairl C, Tinsley M, Cannon TD, Lavin A (2009). Dysbindin modulates prefrontal cortical glutamatergic circuits and working memory function in mice. Neuropsychopharmacology 34: 2601-2608.

Jessen F, Scherk H, Traber F, Theyson S, Berning J, Tepest R et al (2006). Proton magnetic resonance spectroscopy in subjects at risk for schizophrenia. Schizophr Res 87: 81-88.

Job DE, Whalley HC, Johnstone EC, Lawrie SM (2005). Grey matter changes over time in high risk subjects developing schizophrenia. Neuroimage 25: 1023-1030. 
Job DE, Whalley HC, McConnell S, Glabus M, Johnstone EC, Lawrie SM (2003). Voxel-based morphometry of grey matter densities in subjects at high risk of schizophrenia. Schizophr Res 64: 1-13.

Johnstone EC, Cosway R, Lawrie SM (2002). Distinguishing characteristics of subjects with good and poor early outcome in the Edinburgh High-Risk Study. Br J Psychiatry Suppl 43: s26-s29.

Jones EG (1997). Cortical development and thalamic pathology in schizophrenia. Schizophr Bull 23: 483-501.

Jones P, Rodgers B, Murray R, Marmot M (1994). Child development risk factors for adult schizophrenia in the British 1946 birth cohort. Lancet 344: 1398-1402.

Joyce EM, Roiser JP (2007). Cognitive heterogeneity in schizophrenia. Curr Opin Psychiatry 20: 268-272.

Jung WH, Kim JS, Jang JH, Choi JS, Jung MH, Park JY et al (2009). Cortical thickness reduction in individuals at ultra-high-risk for psychosis. Schizophr Bull (e-pub ahead of print 21 December 2009, doi:10.1093/schbul/sbp151)

Karayiorgou M, Gogos JA (1997). Dissecting the genetic complexity of schizophrenia. Mol Psychiatry 2: 211-223.

Keefe RS, Perkins DO, Gu H, Zipursky RB, Christensen BK, Lieberman JA (2006). A longitudinal study of neurocognitive function in individuals at-risk for psychosis. Schizophr Res 88: 26-35.

Keefe RS, Roitman SE, Harvey PD, Blum CS, DuPre RL, Prieto DM et al (1995). A pen-and-paper human analogue of a monkey prefrontal cortex activation task: spatial working memory in patients with schizophrenia. Schizophr Res 17: 25-33.

Keefe RS, Silverman JM, Roitman SE, Harvey PD, Duncan MA, Alroy D et al (1994). Performance of nonpsychotic relatives of schizophrenic patients on cognitive tests. Psychiatry Res 53: 1-12.

Kendler KS, Diehl SR (1993). The genetics of schizophrenia: a current, geneticepidemiologic perspective. Schizophr Bull 19: 261-285.

Kerns JG, Berenbaum H (2002). Cognitive impairments associated with formal thought disorder in people with schizophrenia. J Abnorm Psychol 111: 211-224.

Kerns JG, Cohen JD, MacDonald III AW, Johnson MK, Stenger VA, Aizenstein H et al (2005). Decreased conflict- and error-related activity in the anterior cingulate cortex in subjects with schizophrenia. Am J Psychiatry 162: 1833-1839.

Kimberg DY, D'Esposito M (2003). Cognitive effects of the dopamine receptor agonist pergolide. Neuropsychologia 41: 1020-1027.

Kraepelin E (1919, 1971). Dementia praecox and paraphrenia. Robert E. Krieger Publishing Co. Inc.: Huntington, NY.

Kreher DA, Goff D, Kuperberg GR (2009). Why all the confusion? Experimental task explains discrepant semantic priming effects in schizophrenia under 'automatic' conditions: evidence from event-related potentials. Schizophr Res 111: 174-181.

Kuha A, Tuulio-Henriksson A, Eerola M, Perala J, Suvisaari J, Partonen T et al (2007). Impaired executive performance in healthy siblings of schizophrenia patients in a population-based study. Schizophr Res 92: 142-150.

Lencz T, Smith C, McLaughlin D, Auther A, Nakayama E, Hovey L et al (2006). Generalized and specific neurocognitive deficits in prodromal schizophrenia. Biol Psychiatry 59: 863-871.

Lenior ME, Dingemans PM, Linszen DH, de Haan L, Schene AH (2001). Social functioning and the course of early-onset schizophrenia: five-year follow-up of a psychosocial intervention. Br J Psychiatry 179: 53-58.

Leweke FM, Giuffrida A, Wurster U, Emrich HM, Piomelli D (1999). Elevated endogenous cannabinoids in schizophrenia. Neuroreport 10: 1665-1669.

Lewis DA, Cho RY, Carter CS, Eklund K, Forster S, Kelly MA et al (2008a). Subunitselective modulation of GABA type A receptor neurotransmission and cognition in schizophrenia. Am J Psychiatry 165: 1585-1593.

Lewis DA, Gonzalez-Burgos G (2008b). Neuroplasticity of neocortical circuits in schizophrenia. Neuropsychopharmacology 33: 141-165.

Lewis DA, Hashimoto T, Volk DW (2005). Cortical inhibitory neurons and schizophrenia. Nat Rev Neurosci 6: 312-324. This review examines evidence for the role of inhibitory neurons in higher cognitive dysfunction in schizophrenia, specifically focusing on parvalbumin-expressing GABA neurons and gamma band oscillations.

Li BM, Mei ZT (1994). Delayed-response deficit induced by local injection of the alpha 2-adrenergic antagonist yohimbine into the dorsolateral prefrontal cortex in young adult monkeys. Behav Neural Biol 62: 134-139.

Lidow MS, Elsworth JD, Goldman-Rakic PS (1997). Down-regulation of the D1 and D5 dopamine receptors in the primate prefrontal cortex by chronic treatment with antipsychotic drugs. J Pharmacol Exp Ther 281: 597-603.

Liston C, Matalon S, Hare TA, Davidson MC, Casey BJ (2006). Anterior cingulate and posterior parietal cortices are sensitive to dissociable forms of conflict in a task-switching paradigm. Neuron 50: 643-653.

Logothetis NK, Pauls J, Augath M, Trinath T, Oeltermann A (2001). Neurophysiological investigation of the basis of the fMRI signal. Nature 412: 150-157. This paper revealed that local field potentials yield a better estimate of bloodoxygen-level-dependent (BOLD) fMRI response than spiking activity, which suggested that BOLD response may reflect input and intracortical processing of a region as opposed to its spiking output.

Lovinger DM (2008). Presynaptic modulation by endocannabinoids. Handb Exp Pharmacol 184: 435-477.

MacDonald III AW, Carter CS (2003a). Event-related FMRI study of context processing in dorsolateral prefrontal cortex of patients with schizophrenia. $J$ Abnorm Psychol 112: 689-697.

MacDonald III AW, Carter CS, Kerns JG, Ursu S, Barch DM, Holmes AJ et al (2005). Specificity of prefrontal dysfunction and context processing deficits to schizophrenia in never-medicated patients with first-episode psychosis. Am J Psychiatry 162: 475-484.

MacDonald III AW, Cohen JD, Stenger VA, Carter CS (2000). Dissociating the role of the dorsolateral prefrontal and anterior cingulate cortex in cognitive control. Science 288: 1835-1838. This paper provides evidence that the DLPFC and anterior cingulate perform separable roles in the cognitive control process, namely that the DLPFC is active under conditions that require cognitive control, while the ACC is active during conditions requiring conflict monitoring.

MacDonald III AW, Pogue-Geile MF, Johnson MK, Carter CS (2003b). A specific deficit in context processing in the unaffected siblings of patients with schizophrenia. Arch Gen Psychiatry 60: 57-65. This paper shows genetic susceptibility for context processing deficits by showing that schizophrenia patients and their unaffected siblings show a specific deficit in context processing in comparison to healthy controls.

Maes JH, Bouwman BM, Vossen JM (2001). Effects of $d$-amphetamine on the performance of rats in an animal analogue of the $\mathrm{A}-\mathrm{X}$ continuous performance test. J Psychopharmacol 15: 23-28.

Manoach DS, Press DZ, Thangaraj V, Searl MM, Goff DC, Halpern E et al (1999). Schizophrenic subjects activate dorsolateral prefrontal cortex during a working memory task, as measured by fMRI. Biol Psychiatry 45: 1128-1137.

Markov V, Krug A, Krach S, Jansen A, Eggermann T, Zerres Ket al (2010). Impact of schizophrenia-risk gene dysbindin 1 on brain activation in bilateral middle frontal gyrus during a working memory task in healthy individuals. Hum Brain Mapp 31: 266-275.

Marrs W, Kuperman J, Avedian T, Roth RH, Jentsch JD (2005). Alpha-2 adrenoceptor activation inhibits phencyclidine-induced deficits of spatial working memory in rats. Neuropsychopharmacology 30: 1500-1510.

Mattay VS, Callicott JH, Bertolino A, Heaton I, Frank JA, Coppola R et al (2000). Effects of dextroamphetamine on cognitive performance and cortical activation. Neuroimage 12: 268-275.

McClure MM, Barch DM, Romero MJ, Minzenberg MJ, Triebwasser J, Harvey PD et al (2007). The effects of guanfacine on context processing abnormalities in schizotypal personality disorder. Biol Psychiatry 61: 1157-1160.

McGlashan TH (2001). Structured Interview for Prodromal Syndromes (SIPS). Yale University: New Haven, CT.

McGlashan TH, Hoffman RE (2000). Schizophrenia as a disorder of developmentally reduced synaptic connectivity. Arch Gen Psychiatry 57: 637-648.

McGurk SR, Meltzer HY (2000a). The role of cognition in vocational functioning in schizophrenia. Schizophr Res 45: 175-184.

McGurk SR, Moriarty PJ, Harvey PD, Parrella M, White L, Friedman J et al (2000b). Relationship of cognitive functioning, adaptive life skills, and negative symptom severity in poor-outcome geriatric schizophrenia patients. J Neuropsychiatry Clin Neurosci 12: 257-264.

Mei L, Xiong WC (2008). Neuregulin 1 in neural development, synaptic plasticity and schizophrenia. Nat Rev Neurosci 9: 437-452.

Meltzer HY, Huang M (2008). In vivo actions of atypical antipsychotic drug on serotonergic and dopaminergic systems. Prog Brain Res 172: 177-197.

Miller EK (2000). The prefrontal cortex and cognitive control. Nat Rev Neurosci 1: 59-65.

Miller EK, Cohen JD (2001). An integrative theory of prefrontal cortex function. Annu Rev Neurosci 24: 167-202. An influential review that proposed a model of prefrontal cortex function and cognitive control such that the prefrontal cortex actively maintains 'rules' online in order to evaluate incoming information as well as internal states to guide response selection toward a current goal.

Miller TJ, McGlashan TH, Rosen JL, Somjee L, Markovich PJ, Stein K et al (2002). Prospective diagnosis of the initial prodrome for schizophrenia based on the Structured Interview for Prodromal Syndromes: preliminary evidence of interrater reliability and predictive validity. Am J Psychiatry 159: 863-865.

Minzenberg MJ, Carter CS (2008a). Modafinil: a review of neurochemical actions and effects on cognition. Neuropsychopharmacology 33: 1477-1502.

Minzenberg MJ, Laird AR, Thelen S, Carter CS, Glahn DC (2009). Meta-analysis of 41 functional neuroimaging studies of executive function in schizophrenia. Arch Gen Psychiatry 66: 811-822. This meta-analysis used activation likelihood estimation modeling to examine functionality of the cognitive control 
network across neuroimaging studies of executive function and revealed that patients with schizophrenia show altered activity with deficits in the dorsolateral prefrontal cortex, anterior cingulate cortex, and mediodorsal nucleus of the thalamus.

Minzenberg MJ, Poole JH, Benton C, Vinogradov S (2004). Association of anticholinergic load with impairment of complex attention and memory in schizophrenia. Am J Psychiatry 161: 116-124.

Minzenberg MJ, Watrous AJ, Yoon JH, Ursu S, Carter CS (2008b). Modafinil shifts human locus coeruleus to low-tonic, high-phasic activity during functional MRI. Science 322: 1700-1702.

Mirsky AF (1969). Neuropsychological bases of schizophrenia. Annu Rev Psychol 20: 321-348.

Miyake A, Shah P (1999). Models of Working Memory: Mechanisms of Active Maintenance and Executive Control. Cambridge University Press: New York, NY.

Mohamed S, Paulsen JS, O'Leary D, Arndt S, Andreasen N (1999). Generalized cognitive deficits in schizophrenia: a study of first-episode patients. Arch Gen Psychiatry 56: 749-754.

Molholm S, Martinez A, Ritter W, Javitt DC, Foxe JJ (2005). The neural circuitry of pre-attentive auditory change-detection: an fMRI study of pitch and duration mismatch negativity generators. Cereb Cortex 15: 545-551.

Montgomery JH, Byerly M, Carmody T, Li B, Miller DR, Varghese F et al (2004). An analysis of the effect of funding source in randomized clinical trials of second generation antipsychotics for the treatment of schizophrenia. Control Clin Trials 25: 598-612.

Morey RA, Inan S, Mitchell TV, Perkins DO, Lieberman JA, Belger A (2005). Imaging frontostriatal function in ultra-high-risk, early, and chronic schizophrenia during executive processing. Arch Gen Psychiatry 62: 254-262.

Moriarty PJ, Lieber D, Bennett A, White L, Parrella M, Harvey PD et al (2001). Gender differences in poor outcome patients with lifelong schizophrenia. Schizophr Bull 27: 103-113.

Morice R, McNicol D (1985). The comprehension and production of complex syntax in schizophrenia. Cortex 21: 567-580.

Moron JA, Brockington A, Wise RA, Rocha BA, Hope BT (2002). Dopamine uptake through the norepinephrine transporter in brain regions with low levels of the dopamine transporter: evidence from knock-out mouse lines. J Neurosci 22: 389-395.

Mulet B, Valero J, Gutierrez-Zotes A, Montserrat C, Cortes MJ, Jariod M et al (2007). Sustained and selective attention deficits as vulnerability markers to psychosis. Eur Psychiatry 22: 171-176.

Munafo MR, Bowes L, Clark TG, Flint J (2005). Lack of association of the COMT (Val158/108 Met) gene and schizophrenia: a meta-analysis of case-control studies. Mol Psychiatry 10: 765-770.

Murayama Y, Biebetamann F, Meinecke FC, Muller KR, Augath M, Oeltermann A et al (2010). Relationship between neural and hemodynamic signals during spontaneous activity studied with temporal kernel CCA. Magn Reson Imaging (e-pub ahead of print 20 January 2010, doi:10.1016/j.mn.2009.12.016).

Nahas Z, George MS, Horner MD, Markowitz JS, Li X, Lorberbaum JP et al (2003). Augmenting atypical antipsychotics with a cognitive enhancer (donepezil) improves regional brain activity in schizophrenia patients: a pilot double-blind placebo controlled BOLD fMRI study. Neurocase 9: 274-282.

Neuhaus AH, Opgen-Rhein C, Urbanek C, Hahn E, Ta TM, Seidelsohn M et al (2009). COMT Val 158 Met polymorphism is associated with cognitive flexibility in a signal discrimination task in schizophrenia. Pharmacopsychiatry 42: 141-144.

Newell KA, Deng C, Huang XF (2006). Increased cannabinoid receptor density in the posterior cingulate cortex in schizophrenia. Exp Brain Res 172: 556-560.

Nieman D, Becker H, van de Fliert R, Plat N, Bour L, Koelman H et al (2007). Antisaccade task performance in patients at ultra high risk for developing psychosis. Schizophr Res 95: 54-60.

Niendam TA, Bearden CE, Johnson JK, McKinley M, Loewy R, O'Brien M et al (2006). Neurocognitive performance and functional disability in the psychosis prodrome. Schizophr Res 84: 100-111.

Niendam TA, Bearden CE, Rosso IM, Sanchez LE, Hadley T, Nuechterlein KH et al (2003). A prospective study of childhood neurocognitive functioning in schizophrenic patients and their siblings. Am J Psychiatry 160: 2060-2062.

Niendam TA, Bearden CE, Zinberg J, Johnson JK, O'Brien M, Cannon TD (2007). The course of neurocognition and social functioning in individuals at ultra high risk for psychosis. Schizophr Bull 33: 772-781. This paper shows that baseline neuropsychological functioning is not predictive of psychosocial and clinical outcome in clinical high-risk youth, although the improvement in cognitive functioning over follow-up is associated with improvement in psychosocial and clinical symptoms.

Niessing J, Ebisch B, Schmidt KE, Niessing M, Singer W, Galuske RA (2005). Hemodynamic signals correlate tightly with synchronized gamma oscillations. Science 309: 948-951.
Nuechterlein KH, Dawson ME (1984). Information processing and attentional functioning in the developmental course of schizophrenic disorders. Schizophr Bull 10: 160-203.

O'Donovan MC, Craddock NJ, Owen MJ (2009). Genetics of psychosis; insights from views across the genome. Hum Genet 126: 3-12.

Okochi T, Ikeda M, Kishi T, Kawashima K, Kinoshita Y, Kitajima T et al (2009). Meta-analysis of association between genetic variants in COMT and schizophrenia: an update. Schizophr Res 110: 140-148.

Olincy A, Harris JG, Johnson LL, Pender V, Kongs S, Allensworth D et al (2006). Proof-of-concept trial of an alpha7 nicotinic agonist in schizophrenia. Arch Gen Psychiatry 63: 630-638.

Otani S, Daniel H, Roisin MP, Crepel F (2003). Dopaminergic modulation of longterm synaptic plasticity in rat prefrontal neurons. Cereb Cortex 13: 1251-1256.

Pantelis C, Velakoulis D, McGorry PD, Wood SJ, Suckling J, Phillips LJ et al (2003). Neuroanatomical abnormalities before and after onset of psychosis: a crosssectional and longitudinal MRI comparison. Lancet 361: 281-288. This paper provides evidence that reductions in frontal and temporal gray matter may be associated with the transition to psychosis in individuals who show clinical signs of risk.

Pantelis C, Yucel M, Wood SJ, Velakoulis D, Sun D, Berger G et al (2005). Structural brain imaging evidence for multiple pathological processes at different stages of brain development in schizophrenia. Schizophr Bull 31: 672-696.

Park S, Holzman PS (1992). Schizophrenics show spatial working memory deficits. Arch Gen Psychiatry 49: 975-982.

Patil ST, Zhang L, Martenyi F, Lowe SL, Jackson KA, Andreev BV et al (2007). Activation of mGlu2/3 receptors as a new approach to treat schizophrenia: a randomized Phase 2 clinical trial. Nat Med 13: 1102-1107.

Perlstein WM, Carter CS, Noll DC, Cohen JD (2001). Relation of prefrontal cortex dysfunction to working memory and symptoms in schizophrenia. Am J Psychiatry 158: 1105-1113.

Phillips LJ, Velakoulis D, Pantelis C, Wood S, Yuen HP, Yung AR et al (2002). Nonreduction in hippocampal volume is associated with higher risk of psychosis. Schizophr Res 58: 145-158.

Posner MI, Abdullaev YG (1996). What to Image? Anatomy, Circuity and Plasticity of Human Brain Function. Academic Press: New York, NY.

Posner MI, Petersen SE (1990). The attention system of the human brain. Annu Rev Neurosci 13: 25-42.

Prata DP, Mechelli A, Fu CH, Picchioni M, Kane F, Kalidindi S et al (2009). Opposite effects of catechol-O-methyltransferase Val158Met on cortical function in healthy subjects and patients with schizophrenia. Biol Psychiatry 65: 473-480.

Pukrop R, Ruhrmann S, Schultze-Lutter F, Bechdolf A, Brockhaus-Dumke A, Klosterkotter J (2007). Neurocognitive indicators for a conversion to psychosis: comparison of patients in a potentially initial prodromal state who did or did not convert to a psychosis. Schizophr Res 92: 116-125.

Pukrop R, Schultze-Lutter F, Ruhrmann S, Brockhaus-Dumke A, Tendolkar I, Bechdolf $A$ et al (2006). Neurocognitive functioning in subjects at risk for a first episode of psychosis compared with first- and multiple-episode schizophrenia. J Clin Exp Neuropsychol 28: 1388-1407.

Ragland JD, Laird AR, Ranganath C, Blumenfeld RS, Gonzales SM, Glahn DC (2009). Prefrontal activation deficits during episodic memory in schizophrenia. Am J Psychiatry 166: 863-874.

Ranganath C, Minzenberg MJ, Ragland JD (2008). The cognitive neuroscience of memory function and dysfunction in schizophrenia. Biol Psychiatry 64: 18-25.

Reichenberg A, Caspi A, Harrington H, Houts R, Keefe RS, Murray RM et al (2010). Static and dynamic cognitive deficits in childhood preceding adult schizophrenia: a 30-year study. Am J Psychiatry 167: 160-169.

Riba J, Rodriguez-Fornells A, Morte A, Munte TF, Barbanoj MJ (2005). Noradrenergic stimulation enhances human action monitoring. J Neurosci 25: 4370-4374.

Riley EM, McGovern D, Mockler D, Doku VC, OCeallaigh S, Fannon DG et al (2000). Neuropsychological functioning in first-episode psychosis - evidence of specific deficits. Schizophr Res 43: 47-55.

Rissman J, Gazzaley A, D’Esposito M (2004). Measuring functional connectivity during distinct stages of a cognitive task. Neuroimage 23: 752-763.

Roesch-Ely D, Scheffel H, Weiland S, Schwaninger M, Hundemer HP, Kolter Tet al (2005). Differential dopaminergic modulation of executive control in healthy subjects. Psychopharmacology (Berl) 178: 420-430.

Russell AJ, Munro JC, Jones PB, Hemsley DR, Murray RM (1997). Schizophrenia and the myth of intellectual decline. Am J Psychiatry 154: 635-639.

Sawaguchi T, Goldman-Rakic PS (1994). The role of D1-dopamine receptor in working memory: local injections of dopamine antagonists into the prefrontal cortex of rhesus monkeys performing an oculomotor delayed-response task. J Neurophysiol 71: 515-528. 
Saykin AJ, Gur RC, Gur RE, Mozley PD, Mozley LH, Resnick SM et al (1991). Neuropsychological function in schizophrenia. Selective impairment in memory and learning. Arch Gen Psychiatry 48: 618-624.

Saykin AJ, Shtasel DL, Gur RE, Kester DB, Mozley LH, Stafiniak P et al (1994). Neuropsychological deficits in neuroleptic naive patients with first-episode schizophrenia. Arch Gen Psychiatry 51: 124-131.

Scholes KE, Harrison BJ, O'Neill BV, Leung S, Croft RJ, Pipingas A et al (2007). Acute serotonin and dopamine depletion improves attentional control: findings from the stroop task. Neuropsychopharmacology 32: 1600-1610.

Schuepbach D, Keshavan MS, Kmiec JA, Sweeney JA (2002). Negative symptom resolution and improvements in specific cognitive deficits after acute treatment in first-episode schizophrenia. Schizophr Res 53: 249-261.

Schultz W, Dayan P, Montague PR (1997). A neural substrate of prediction and reward. Science 275: 1593-1599.

Schwartz BL, Rosse RB, Deutsch SI (1992). Toward a neuropsychology of memory in schizophrenia. Psychopharmacol Bull 28: 341-351.

Seamans JK, Yang CR (2004). The principal features and mechanisms of dopamine modulation in the prefrontal cortex. Prog Neurobiol 74: 1-58.

Selemon LD, Goldman-Rakic PS (1999). The reduced neuropil hypothesis: a circuit based model of schizophrenia. Biol Psychiatry 45: 17-25. This post-mortem study provides support for the 'pruning' hypothesis of schizophrenia by suggesting that reductions in neuropil, and therefore connections between neurons, are found within the prefrontal cortex of individuals with schizophrenia and account for the reduced cortical thinkness found in this area.

Selemon LD, Rajkowska G, Goldman-Rakic PS (1995). Abnormally high neuronal density in the schizophrenic cortex. A morphometric analysis of prefrontal area 9 and occipital area 17. Arch Gen Psychiatry 52: 805-818; discussion 819-820.

Servan-Schreiber D, Carter CS, Bruno RM, Cohen JD (1998). Dopamine and the mechanisms of cognition: Part II. $D$-amphetamine effects in human subjects performing a selective attention task. Biol Psychiatry 43: 723-729.

Sesack SR, Hawrylak VA, Matus C, Guido MA, Levey Al (1998). Dopamine axon varicosities in the prelimbic division of the rat prefrontal cortex exhibit sparse immunoreactivity for the dopamine transporter. J Neurosci 18: 2697-2708.

Shallice T (1988). From Neuropsychology to Mental Structure. Cambridge University Press: Cambridge, MA

Shenton ME, Dickey CC, Frumin M, McCarley RW (2001). A review of MRI findings in schizophrenia. Schizophr Res 49: 1-52.

Silverstein S, Uhlhaas PJ, Essex B, Halpin S, Schall U, Carr V (2006). Perceptual organization in first episode schizophrenia and ultra-high-risk states. Schizophr Res 83: 41-52.

Silverstein SM, Knight RA, Schwarzkopf SB, West LL, Osborn LM, Kamin D (1996). Stimulus configuration and context effects in perceptual organization in schizophrenia. J Abnorm Psychol 105: 410-420.

Simon AE, Cattapan-Ludewig K, Zmilacher S, Arbach D, Gruber K, Dvorsky DN et al (2007). Cognitive functioning in the schizophrenia prodrome. Schizophr Bull 33: $761-771$.

Smith CW, Park S, Cornblatt B (2006). Spatial working memory deficits in adolescents at clinical high risk for schizophrenia. Schizophr Res 81: 211-215.

Smith EE, Jonides J (1999). Storage and executive processes in the frontal lobes. Science 283: 1657-1661. A clear and concise review that interpreted the existing literature on storage and executive processes as they relate to prefrontal cortex, with an emphasis on verbal versus spatial storage and inhibitory processes.

Smith TE, Hull JW, Huppert JD, Silverstein SM (2002). Recovery from psychosis in schizophrenia and schizoaffective disorder: symptoms and neurocognitive ratelimiters for the development of social behavior skills. Schizophr Res 55: 229-237.

Snitz BE, MacDonald III A, Cohen JD, Cho RY, Becker T, Carter CS (2005). Lateral and medial hypofrontality in first-episode schizophrenia: functional activity in a medication-naive state and effects of short-term atypical antipsychotic treatment. Am J Psychiatry 162: 2322-2329.

Snitz BE, Macdonald III AW, Carter CS (2006). Cognitive deficits in unaffected firstdegree relatives of schizophrenia patients: a meta-analytic review of putative endophenotypes. Schizophr Bull 32: 179-194.

Sohn MH, Ursu S, Anderson JR, Stenger VA, Carter CS (2000). Inaugural article: the role of prefrontal cortex and posterior parietal cortex in task switching. Proc Natl Acad Sci USA 97: 13448-13453. This paper showed the role of prefrontal and parietal cortices when subjects were asked to prepare for task switching versus adjusting to task demands without preparation.

Steen RG, Hamer RM, Lieberman JA (2005). Measurement of brain metabolites by $1 \mathrm{H}$ magnetic resonance spectroscopy in patients with schizophrenia: a systematic review and meta-analysis. Neuropsychopharmacology 30: 1949-1962.

Stip E, Chouinard S, Boulay LJ (2005). On the trail of a cognitive enhancer for the treatment of schizophrenia. Prog Neuropsychopharmacol Biol Psychiatry 29: 219-232.
Sullivan PF, Kendler KS, Neale MC (2003). Schizophrenia as a complex trait: evidence from a meta-analysis of twin studies. Arch Gen Psychiatry 60: 1187-1192.

Sur C, Mallorga PJ, Wittmann M, Jacobson MA, Pascarella D, Williams JB et al (2003). N-desmethylclozapine, an allosteric agonist at muscarinic 1 receptor, potentiates N-methyl-D-aspartate receptor activity. Proc Natl Acad Sci USA 100: 13674-13679.

Szoke A, Schurhoff F, Meary A, Mathieu F, Chevalier F, Trandafir A et al (2006). Lack of influence of COMT and NET genes variants on executive functions in schizophrenic and bipolar patients, their first-degree relatives and controls. Am J Med Genet B 141B: 504-512.

Takahashi T, Yucel M, Yung AR, Wood SJ, Phillips LJ, Berger GE et al (2008a). Adhesio interthalamica in individuals at high-risk for developing psychosis and patients with psychotic disorders. Prog Neuropsychopharmacol Biol Psychiatry 32: $1708-1714$.

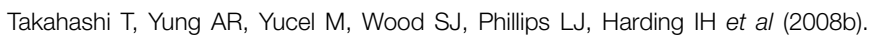
Prevalence of large cavum septi pellucidi in ultra high-risk individuals and patients with psychotic disorders. Schizophr Res 105: 236-244.

Tallon-Baudry C, Bertrand O (1999a). Oscillatory gamma activity in humans and its role in object representation. Trends Cogn Sci 3: 151-162.

Tallon-Baudry C, Bertrand O, Peronnet F, Pernier J (1998). Induced gamma-band activity during the delay of a visual short-term memory task in humans. J Neurosci 18: 4244-4254.

Tallon-Baudry C, Kreiter A, Bertrand O (1999b). Sustained and transient oscillatory responses in the gamma and beta bands in a visual short-term memory task in humans. Vis Neurosci 16: 449-459.

Tamlyn D, McKenna PJ, Mortimer AM, Lund CE, Hammond S, Baddeley AD (1992). Memory impairment in schizophrenia: its extent, affiliations and neuropsychological character. Psychol Med 22: 101-115.

Tan HY, Callicott JH, Weinberger DR (2009). Prefrontal cognitive systems in schizophrenia: towards human genetic brain mechanisms. Cogn Neuropsychiatry 14: 277-298.

Taylor SF, Kornblum S, Minoshima S, Oliver LM, Koeppe RA (1994). Changes in medial cortical blood flow with a stimulus-response compatibility task. Neuropsychologia 32: 249-255.

Thermenos HW, Seidman LJ, Breiter H, Goldstein JM, Goodman JM, Poldrack R et al (2004). Functional magnetic resonance imaging during auditory verbal working memory in nonpsychotic relatives of persons with schizophrenia: a pilot study. Biol Psychiatry 55: 490-500.

Thompson-Schill SL, Bedny M, Goldberg RF (2005). The frontal lobes and the regulation of mental activity. Curr Opin Neurobiol 15: 219-224.

Townsend LA, Malla AK, Norman RM (2001). Cognitive functioning in stabilized firstepisode psychosis patients. Psychiatry Res 104: 119-131.

Tronel S, Feenstra MG, Sara SJ (2004). Noradrenergic action in prefrontal cortex in the late stage of memory consolidation. Learn Mem 11: 453-458.

Turner DC, Clark L, Pomarol-Clotet E, McKenna P, Robbins TW, Sahakian BJ (2004). Modafinil improves cognition and attentional set shifting in patients with chronic schizophrenia. Neuropsychopharmacology 29: 1363-1373.

Ujike H, Takaki M, Nakata K, Tanaka Y, Takeda T, Kodama M et al (2002). CNR1, central cannabinoid receptor gene, associated with susceptibility to hebephrenic schizophrenia. Mol Psychiatry 7: 515-518.

van Erp TG, Saleh PA, Huttunen M, Lonnqvist J, Kaprio J, Salonen O et al (2004). Hippocampal volumes in schizophrenic twins. Arch Gen Psychiatry 61: 346-353.

van Winkel R, Stefanis NC, Myin-Germeys I (2008). Psychosocial stress and psychosis. A review of the neurobiological mechanisms and the evidence for gene-stress interaction. Schizophr Bull 34: 1095-1105.

Velligan DI, Bow-Thomas CC, Mahurin RK, Miller AL, Halgunseth LC (2000). Do specific neurocognitive deficits predict specific domains of community function in schizophrenia? J Nerv Ment Dis 188: 518-524.

Velligan DI, Mahurin RK, Diamond PL, Hazleton BC, Eckert SL, Miller AL (1997). The functional significance of symptomatology and cognitive function in schizophrenia. Schizophr Res 25: 21-31.

Vinogradov S, Fisher M, Warm H, Holland C, Kirshner MA, Pollock BG (2009). The cognitive cost of anticholinergic burden: decreased response to cognitive training in schizophrenia. Am J Psychiatry 166: 1055-1062.

Walterfang M, McGuire PK, Yung AR, Phillips LJ, Velakoulis D, Wood SJ et al (2008a). White matter volume changes in people who develop psychosis. Br J Psychiatry 193: 210-215.

Walterfang M, Yung A, Wood AG, Reutens DC, Phillips L, Wood SJ et al (2008b). Corpus callosum shape alterations in individuals prior to the onset of psychosis. Schizophr Res 103: 1-10.

Watanabe M (1990). Prefrontal unit activity during associative learning in the monkey. Exp Brain Res 80: 296-309.

Watanabe M (1992). Frontal units of the monkey coding the associative significance of visual and auditory stimuli. Exp Brain Res 89: 233-247. 
Wechsler D (1997). WMS-III Administration and Scoring Manual. The Psychological Corporation: San Antonio, TX.

Weinberger DR (1987). Implications of normal brain development for the pathogenesis of schizophrenia. Arch Gen Psychiatry 44: 660-669.

Weinberger DR, Berman KF, Zec RF (1986). Physiologic dysfunction of dorsolateral prefrontal cortex in schizophrenia. I. Regional cerebral blood flow evidence. Arch Gen Psychiatry 43: 114-124. This seminal study showed that dorsolateral prefrontal dysfunction, measured via reduced cerebral blood flow, was most evident in patients with schizophrenia when performing particular cognitive tasks.

Weinberger DR, Gallhofer B (1997). Cognitive function in schizophrenia. Int Clin Psychopharmacol 12(Suppl 4): S29-S36.

Weiss EM, Bilder RM, Fleischhacker WW (2002). The effects of second-generation antipsychotics on cognitive functioning and psychosocial outcome in schizophrenia. Psychopharmacology (Berl) 162: 11-17.

Wendelken C, Ditterich J, Bunge SA, Carter CS (2009). Stimulus and response conflict processing during perceptual decision making. Cogn Affect Behav Neurosci 9: 434-447.

Whalley HC, Simonotto E, Flett S, Marshall I, Ebmeier KP, Owens DG et al (2004). $\mathrm{fMRI}$ correlates of state and trait effects in subjects at genetically enhanced risk of schizophrenia. Brain 127(Part 3): 478-490.

Whalley HC, Simonotto E, Moorhead W, McIntosh A, Marshall I, Ebmeier KP et al (2006). Functional imaging as a predictor of schizophrenia. Biol Psychiatry 60 454-462.

Whittington MA, Faulkner HJ, Doheny HC, Traub RD (2000). Neuronal fast oscillations as a target site for psychoactive drugs. Pharmacol Ther 86: 171-190.

Williams GV, Castner SA (2006). Under the curve: critical issues for elucidating D1 receptor function in working memory. Neuroscience 139: 263-276.

Wilson FA, O'Scalaidhe SP, Goldman-Rakic PS (1994). Functional synergism between putative gamma-aminobutyrate-containing neurons and pyramidal neurons in prefrontal cortex. Proc Natl Acad Sci USA 91: 4009-4013.

Winterer G, Egan MF, Raedler T, Sanchez C, Jones DW, Coppola R et al (2003). P300 and genetic risk for schizophrenia. Arch Gen Psychiatry 60: 1158-1167.

Wirgenes KV, Djurovic S, Sundet K, Agartz I, Mattingsdal M, Athanasiu L et al (2010). Catechol O-methyltransferase variants and cognitive performance in schizophrenia and bipolar disorder versus controls. Schizophr Res 122: 31-37.

Witthaus H, Brune M, Kaufmann C, Bohner G, Ozgurdal S, Gudlowski Y et al (2008). White matter abnormalities in subjects at ultra high-risk for schizophrenia and first-episode schizophrenic patients. Schizophr Res 102: 141-149.

Wolf DH, Gur RC, Valdez JN, Loughead J, Elliott MA, Gur RE et al (2007). Alterations of fronto-temporal connectivity during word encoding in schizophrenia. Psychiatry Res 154: 221-232.

Wolf LE, Cornblatt BA, Roberts SA, Shapiro BM, Erlenmeyer-Kimling L (2002). Wisconsin Card Sorting deficits in the offspring of schizophrenics in the New York High-Risk Project. Schizophr Res 57: 173.

Wood SJ, Berger G, Velakoulis D, Phillips LJ, McGorry PD, Yung AR et al (2003a). Proton magnetic resonance spectroscopy in first episode psychosis and ultra high-risk individuals. Schizophr Bull 29: 831-843.
Wood SJ, Pantelis C, Proffitt T, Phillips LJ, Stuart GW, Buchanan JA et al (2003b). Spatial working memory ability is a marker of risk-for-psychosis. Psychol Med 33: 1239-1247.

Wood SJ, Pantelis C, Velakoulis D, Yucel M, Fornito A, McGorry PD (2008). Progressive changes in the development toward schizophrenia: studies in subjects at increased symptomatic risk. Schizophr Bull 34: 322-329

Wood SJ, Yucel M, Velakoulis D, Phillips LJ, Yung AR, Brewer W et al (2005). Hippocampal and anterior cingulate morphology in subjects at ultra-high-risk for psychosis: the role of family history of psychotic illness. Schizophr Res 75 : 295-301.

Woodward ND, Jayathilake K, Meltzer HY (2007). COMT val108/158met genotype, cognitive function, and cognitive improvement with clozapine in schizophrenia. Schizophr Res 90: 86-96.

Wright IC, Rabe-Hesketh S, Woodruff PW, David AS, Murray RM, Bullmore ET (2000). Meta-analysis of regional brain volumes in schizophrenia. Am J Psychiatry 157: 16-25.

Yarkoni T, Gray JR, Chrastil ER, Barch DM, Green L, Braver TS (2005). Sustained neural activity associated with cognitive control during temporally extended decision making. Brain Res Cogn Brain Res 23: 71-84.

Yeung N, Nystrom LE, Aronson JA, Cohen JD (2006). Between-task competition and cognitive control in task switching. J Neurosci 26: 1429-1438.

Yoon JH, Minzenberg MJ, Ursu S, Walter R, Wendelken C, Ragland JD et al (2008a). Association of dorsolateral prefrontal cortex dysfunction with disrupted coordinated brain activity in schizophrenia: relationship with impaired cognition, behavioral disorganization, and global function. Am J Psychiatry 165: 1006-1014. This paper utilized functional connectivity analysis to show reduced activation of the cognitive control network in schizophrenia during tasks requiring high levels of cognitive control, and this reduction in functional connectivity was associated with aspects of illness presentation, including increased behavioral disorganization and poorer global functioning.

Yoon JH, Tamir D, Minzenberg MJ, Ragland JD, Ursu S, Carter CS (2008b). Multivariate pattern analysis of functional magnetic resonance imaging data reveals deficits in distributed representations in schizophrenia. Biol Psychiatry 64: 1035-1041

Yucel M, Wood SJ, Phillips LJ, Stuart GW, Smith DJ, Yung A et al (2003). Morphology of the anterior cingulate cortex in young men at ultra-high risk of developing a psychotic illness. $\mathrm{Br} J$ Psychiatry 182: 518-524

Zavitsanou K, Garrick T, Huang XF (2004). Selective antagonist [ $\left.{ }^{3} \mathrm{H}\right] \mathrm{SR} 141716 \mathrm{~A}$ binding to cannabinoid CB1 receptors is increased in the anterior cingulate cortex in schizophrenia. Prog Neuropsychopharmacol Biol Psychiatry 28: 355-360.

Zirnheld PJ, Carroll CA, Kieffaber PD, O'Donnell BF, Shekhar A, Hetrick WP (2004). Haloperidol impairs learning and error-related negativity in humans. J Cogn Neurosci 16: 1098-1112. 